\title{
Residential-Source Emission Inventory for the Niger Delta - A Methodological Approach
}

\author{
Fagbeja Mofoluso Ayodele ${ }^{1}$, Hill Jennifer ${ }^{2}$, Chatterton Tim ${ }^{3}$, Longhurst James ${ }^{3} \&$ Akinyede Joseph ${ }^{4}$ \\ ${ }^{1}$ Strategic Space Applications Department, National Space Research and Development Agency (NASRDA), \\ Abuja, Nigeria \\ ${ }^{2}$ Department of Geography and Environmental Management, University of the West of England, Bristol, UK \\ ${ }^{3}$ Air Quality Management Resource Centre, University of the West of England, Bristol, UK \\ ${ }^{4}$ Centre for Space Science and Technology Education (CSSTE), Obafemi Awolowo University, Ile-Ife, Nigeria \\ Correspondence: Fagbeja, Mofoluso Ayodele, Strategic Space Applications, National Space Research and \\ Development Agency, Obasanjo Space Centre, Airport Road, PMB 437 Garki, Abuja, Nigeria. Tel: \\ 234-815-756-4775. E-mail: mfagbee@yahoo.com; Mofoluso.Fagbeja@nasrda.net
}

Received: March 7, 2013 Accepted: May 15, 2013 Online Published: May 27, 2013

doi:10.5539/jsd.v6n6p98 URL: http://dx.doi.org/10.5539/jsd.v6n6p98

\begin{abstract}
This paper describes the methods applied to construct a GIS-based emission inventory infrastructure for specific air pollutants and greenhouse gases released from domestic cooking and lighting in the Niger Delta using publicly accessible data. The purpose is to identify and enhance knowledge of existing data gaps in order to progress the development of appropriate mechanisms to collect data in formats required for more accurate emission estimation. The major data gaps identified, which are demographic, activity-based, emission factors and spatial distribution of sources, are consistent across the majority of developing countries. Consequently, the methodological approach focuses on the use of a series of assumptions, emission factors from regions similar to the Niger Delta, and population estimation techniques to generate input data to support the limited publicly available government and research-based data. Developing countries with similar data limitations will benefit from the transferrable methodology. The infrastructure, which is constructed at $10 \mathrm{~km}$-grid resolutions, produced total emission estimates of $70 \mathrm{kt} / \mathrm{yr} \mathrm{CO}, 50 \mathrm{kt} / \mathrm{yr} \mathrm{NO}$, $3 \mathrm{kt} / \mathrm{yr} \mathrm{PM} 10,2.4 \mathrm{kt} / \mathrm{yr} \mathrm{SO}_{2}, 60 \mathrm{t} / \mathrm{yr} \mathrm{VOC}, 5.7 \mathrm{mt} / \mathrm{yr} \mathrm{CO}_{2}$ and $2 \mathrm{kt} / \mathrm{yr} \mathrm{CH}_{4}$. Domestic lighting using generators and domestic cooking using firewood and kerosene constitute sources of significant emissions of air pollutants in the region. Due to the limited accuracy and completeness of currently available data, the estimates generated have high uncertainties.
\end{abstract}

Keywords: emission inventory, domestic activities, air pollution, data, GIS, developing countries, Niger Delta

\section{Introduction}

Emission inventories play important roles in the assessment, monitoring, modelling and management of emissions of air pollutants and greenhouse gases (GHGs), which have various impacts on human health, vegetation and climate (Banerjee et al., 2011; de Kluizenaar et al., 2001; Parra et al., 2005; Wang et al., 2010). Due to their importance in forming the basis of modelling studies, and eventually mitigation policies, it is important that emission inventories produce emission estimates that are accurate (Su et al., 2011). In addition, spatially resolved inventories afford air quality specialists and decision makers the ability to visualise the distribution of emissions over a geographic region. Maps of the distribution of emissions help identify areas with high, medium and low densities of pollutants (De Kluizenaar et al., 2001; Para et al., 2005). This further enhances health and environmental risk assessment, source-receptor analysis, dispersion modelling of pollution from sources and the deployment of appropriate policies and measures to reduce emissions. Available emission inventories estimate emissions of pollutants from residential sources due to their contribution to indoor and ambient air pollution (Alves et al., 2011; Bahera et al., 2011; MacCarthy et al., 2010; Pastorello et al., 2011; Streets et al., 2003). The majority of these studies identified fossil fuel consumption, bio-fuel use (for domestic cooking, lighting and heating) and boilers (for heating) as main activities that release air pollutants and GHGs from residences. 
This paper presents a residential-source emission inventory infrastructure, which relies on a bottom-up approach to estimate emissions from specific domestic activities within the Niger Delta region using publicly available local data, assumptions and emission factors (Lindley et al., 1996; MacCarthy et al., 2010). The specific domestic activities considered in the inventory are cooking and lighting using generators. The burning of fossil fuels in lanterns and the use of candles for domestic lighting are not considered in this study due to a lack of adequate information on their usage. This paper also describes the methodological approach to estimate emissions of the most frequently and routinely monitored air pollutants - nitrogen dioxide $\left(\mathrm{NO}_{2}\right)$, sulphur dioxide $\left(\mathrm{SO}_{2}\right)$, particulate matter $\left(\mathrm{PM}_{10}\right)$, volatile organic compounds (VOC) and carbon monoxide (CO) as well as the important GHGs - carbon dioxide $\left(\mathrm{CO}_{2}\right)$ and methane $\left(\mathrm{CH}_{4}\right)$ from these domestic activities in the Niger Delta. The emission estimation process used hourly profiles to generate annual estimates of emissions. The Niger Delta region exemplifies developing regions and countries with considerable limitations in publicly available government and research-based data. The majority of developing countries are faced with challenges of inadequate, inappropriate and lack of high quality data required for the accurate estimation of emissions from various anthropogenic activities (Duduta \& Bishins, 2010). Publicly available data in these countries are not usually reliable and sufficient to develop a verifiable emissions inventory. As a result, the majority of developing countries in Africa, Asia and South America lack verifiable emissions inventories. The developing countries with inventories are faced with issues of quality assurance and inventory comparisons arising from the reliability of emission factors, inconsistent input activity data, methodologies, algorithms and a lack of capacity to undertake direct emissions measurements (Lim et al., 1999). For instance, the South African Department for Environmental Affairs and Tourism (DEAT) has the only verifiable emission inventory in sub-Saharan Africa (DEAT, 2007; DEAT, 2008). In view of data limitations, this paper presents the assumptions and methods applied to generate data in an appropriate format (MacCarthy et al., 2010). The process identified currently existing gaps in the data required for the generation of accurate emission estimates from domestic activities in the region. The methods presented in this paper are transferrable to other developing countries with similar limitations in demographic, activity-based and spatial data required for accurate emission estimation. The estimates generated from the process are presented in the form of maps and charts. Although the infrastructure is designed to provide GIS-based mapping and visualisation outputs for emission estimates at high- $(1 \mathrm{~km} \times 1 \mathrm{~km})$, medium- $(10 \mathrm{~km} \times 10 \mathrm{~km})$ and low- $(20 \mathrm{~km} \times 20 \mathrm{~km})$ grid resolutions, the results presented in this paper are those generated at the medium-grid resolution.

\subsection{Emissions from Domestic Activities in the Niger Delta}

The Niger Delta region of Nigeria consists of nine of the thirty-six States of the Nigerian Federation. The region is located in the southern part of Nigeria in Western Africa (See Appendix). According to the Nigerian National Bureau of Statistics (NBS), based on the 2006 National Population Census, the 2006 population estimate for the Niger Delta is $31,224,177$. This constitutes approximately $15 \%$ of the total population of Nigeria (NBS, 2006). According to the Niger Delta Development Masterplan report developed by the Niger Delta Development Commission (NDDC), there are an estimated 13,329 settlements in the Niger Delta (NDDC, 2006). According to the report, 13,231 (approximately 99\%) of these settlements have an average population below 20,000 people. Settlements with less than 5,000 people constitute an estimated $94 \%$ of the total settlements. Only about 98 settlements ( $1 \%$ of total settlements) have populations above 20,000 and are considered to be urban settlements. However, the specific location and population of all the individual settlements are not publicly available from the Nigerian National Population Commission (NPC) or any other source. The lowest category of population estimates available from the NPC is at the Local Government Area (LGA) level (NBS, 2006). Figure 1 shows the population density map of the Niger Delta region. 


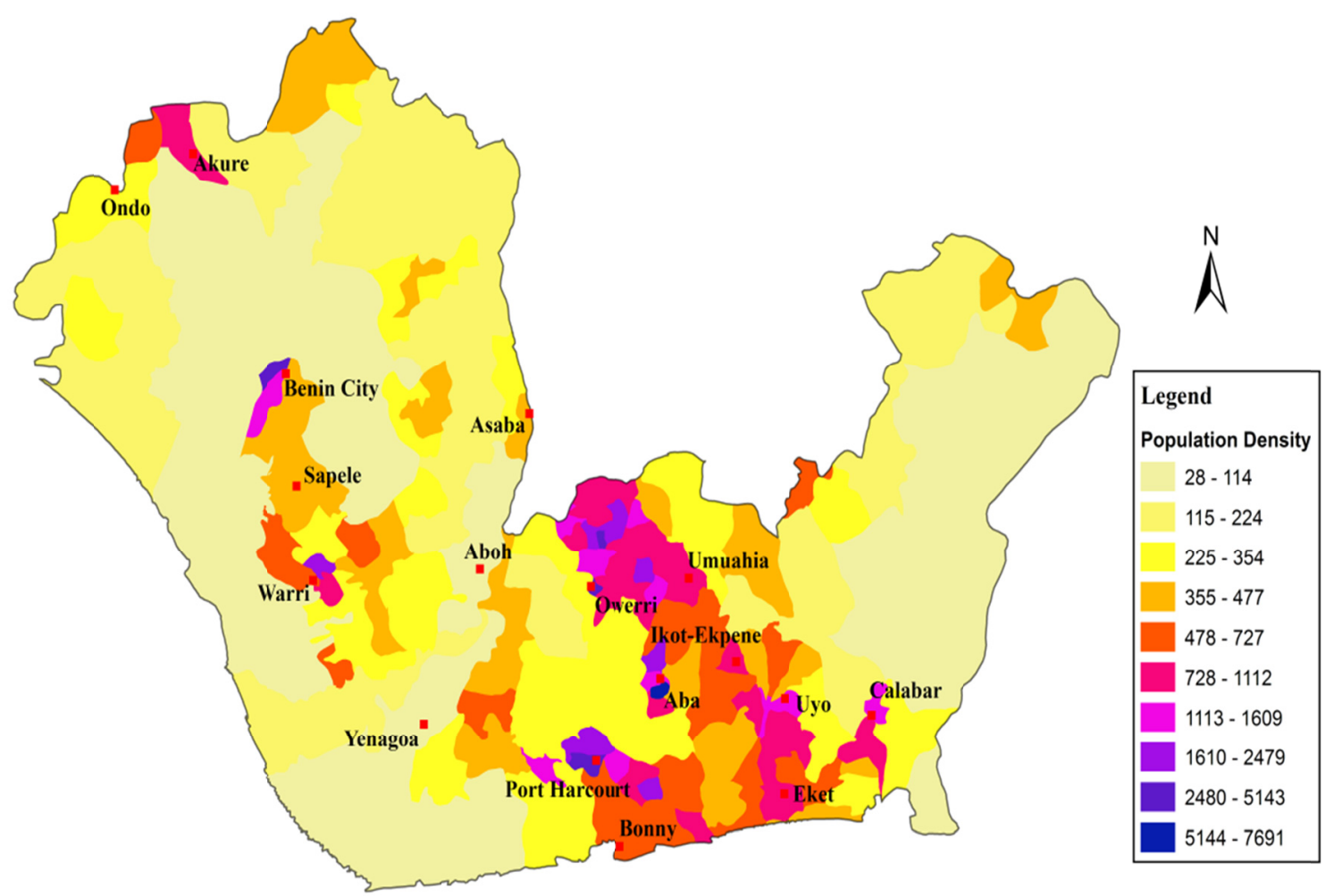

Figure 1. Map showing population density by local government areas in the Niger Delta

Oil and gas exploration in the Niger Delta has resulted in a high rate of pollution-related anthropogenic activities due to high rates of urbanisation, industrialisation, gas flaring, and burning of bio-fuel (Note 1) and liquid fuel for domestic cooking, domestic lighting, and industrial electricity (NBS, 2006b; Ukoli, 2001; UNDP, 2006). According to Hicks (1998), the majority of developing countries experience high rates of urbanisation and industrialisation, which are usually not accompanied by commensurate economic and infrastructure growth. This results in urban and rural poverty, lack of access to infrastructure such as power and clean fuel for domestic and industrial use. According to the United Nations Human Development Report (UNHDR) for 2007-2008, an estimated $92 \%$ of Nigerians lived below the income poverty line of $\$ 2$ a day (UNDP, 2007). In the Niger Delta region, $66 \%$ of the population self-classify as poor (NBS, 2006b). Due to poverty and a lack of access to infrastructure, many urban and rural dwellers in the Niger Delta rely on burning of kerosene, charcoal and wood for cooking and domestic lighting. Due to the lack of adequate electricity supply from the national grid, the majority of homes burn fossil fuels to generate electricity. These are some of the underlying factors responsible for air pollution in the region. According to the National Bureau of Statistics (NBS), an estimated $70 \%$ of Nigerians rely on firewood for cooking, $27 \%$ depend on the use of kerosene or oil, while $1.5 \%, 1 \%$ and $0.5 \%$ use coal, gas and electricity respectively (NBS, 2005).

This supports the observation of the European Commission Joint Research Centre (EC-JRC) and the Netherlands Environmental Assessment Agency (PBL) through the Emission Database for Global Atmospheric Research (EDGAR) database (EC-JRC/PBL, 2010). The EDGAR database is an inventory of anthropogenic emissions of greenhouse gases and air pollutants at national levels. According to the database, residential activities (Note 2) are major sources of air pollutants in Nigeria, contributing $43 \%$ of $\mathrm{CO} ; 9 \%$ of $\mathrm{NO}_{\mathrm{x}} ; 18 \%$ of $\mathrm{SO}_{2} ; 22 \%$ of $\mathrm{VOC} ; 6 \%$ of inorganic $\mathrm{CO}_{2} ; 43 \%$ of organic $\mathrm{CO}_{2}$; and $4 \%$ of $\mathrm{CH}_{4}$ emissions (EC-JRC/PBL, 2010). The emission estimates available from EC-JRC/PBL (2010) are derived from activity data taken from international data sources and emission factors selected from publications, which could produce national estimates with substantial uncertainties (EC-JRC/PBL, 2010), especially in developing countries with limited data such as Nigeria (See emission estimates in Appendix). The predicted uncertainties in these emission estimates generated from combustion of fossil fuel and bio-fuels range from 10\% to $100 \%$ (EC-JRC/PBL, 2010). Consequently, it is assumed that the majority of the estimates obtained from EC-JRC/PBL (2010) for Nigeria are likely to be highly inaccurate, as they are not the result of detailed surveys of the specific activities, timescales and processes that 
release emissions in Nigeria. An assessment of the uncertainties in the United Kingdom's National Atmospheric Emissions Inventory (NAEI) shows that uncertainties in emission estimates of less than $50 \%$ are achievable through the development of a national or regional emission inventory using site-specific data and relevant proxy information derived from appropriate environmental reporting and regulations (Murrells et al., 2011). Such regulation and reporting frameworks are currently unavailable in most developing countries, including Nigeria. The inventory presented in this paper is the first spatially-resolved inventory designed for the whole of the Niger Delta for the purpose of estimating emissions from residential activities. The paper further demonstrates the functionality of this platform and presents a framework which can be used as a focus for future surveys of emission sources and data collection in the region and other developing countries.

\section{Materials and Methods}

The construction of the GIS-based emission inventory of pollutants and GHGs from domestic cooking and lighting in the Niger Delta followed the process shown in Figure 2. The residential-source inventory for the Niger Delta is designed and constructed using a combination of Microsoft Excel spreadsheets and ESRI ArcGIS (ArcView Desktop) software. The spreadsheet is used to design and construct the basic emission inventory infrastructure where details of the sources are entered and the process of estimating emissions is carried out. The results are then linked to the GIS using the spatial attributes of data and the unique identifiers generated for the $10 \mathrm{~km} \times 10 \mathrm{~km}$ grids covering the Niger Delta. The GIS also serves as the repository of spatial data from which the data contained in the spreadsheets are updated. All the GIS data (ArcView shapefiles) are captured and referenced to Nigerian Transverse Mercator - Mid Belt, Minna Datum. The data are also available in standard geographic coordinate system, WGS 84 datum (Onyeka, 2006).

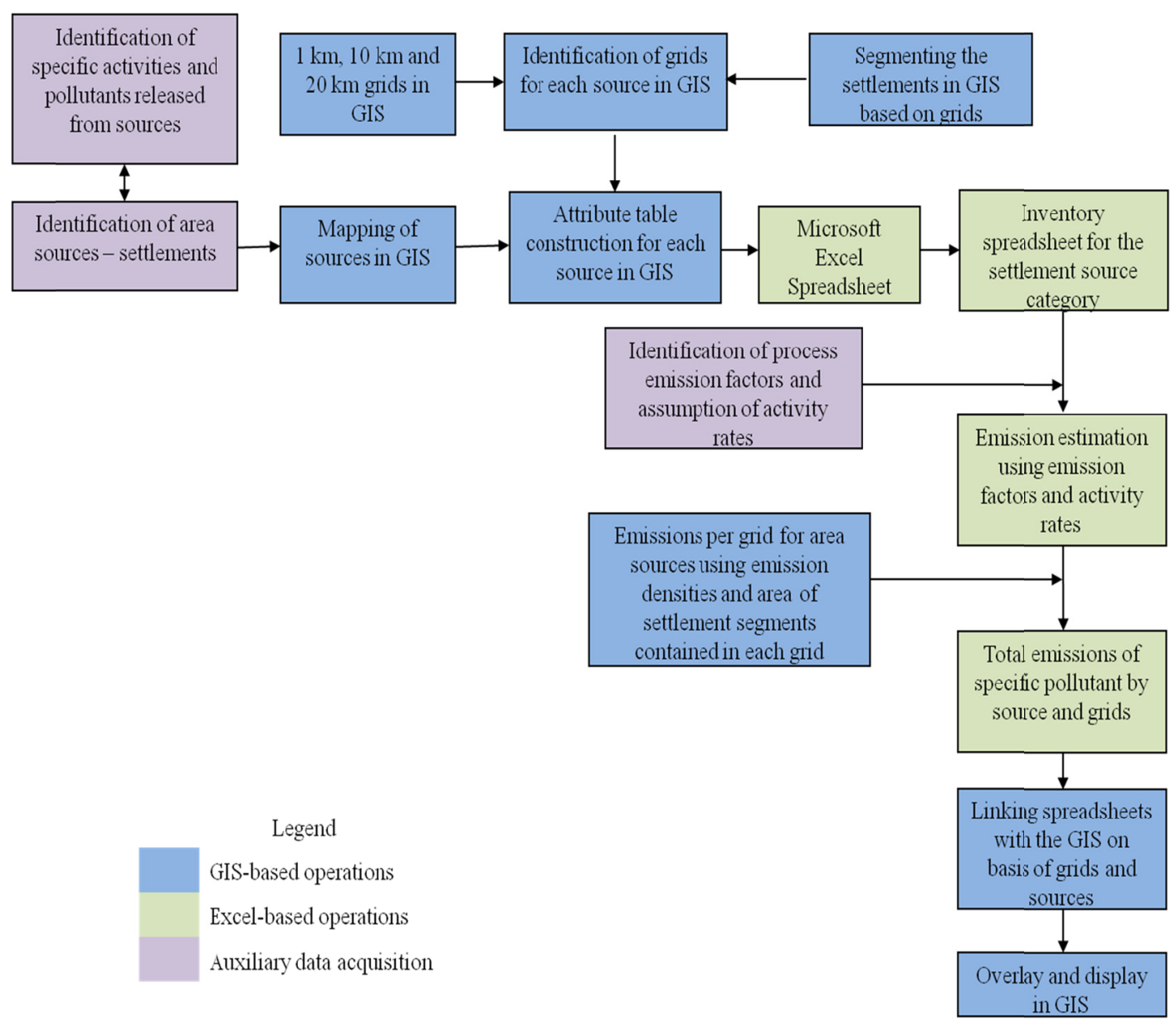

Figure 2. Flow diagram representing the processes followed in the design and construction of the residential-source inventory for the Niger Delta 
The key operations carried out in developing the spatially enabled emission inventory focused on linking the identified sources and the emission estimates with the appropriate grids. Specific GIS processes were applied to allocate emissions from settlements that cut across more than one grid to specific grids based on the portion of the settlements that fell within the grids. The process required the creation of the grids covering the entire study area and generating unique identifiers for these grids. Maps of the extents of the settlements were produced and the area of the settlements estimated. Area segments of settlements were generated in order to allocate portions of settlements to the specific grids they fell into. The unique identifiers of the grids were attached to the settlement segments and the areas of the segments were calculated. From the Excel spreadsheet designed for the inventory, the estimates of emissions from each settlement were generated based on activity, demographic and emission factors data. Based on this, emission estimates for the settlement segments were calculated using emission densities generated for each settlement and the area of each segment. The emission estimates allocated to the grids were used to produce the emission distribution maps for the entire region.

\subsection{Settlement Data}

The residential sources used for the study are represented by the area covered by the settlements in the Niger Delta. A GIS settlements database for the Niger Delta was constructed based on the minor and major urban settlements contained in the 1996 Forestry Management and Evaluation Coordinating Unit (FORMECU) land use and land cover map of Nigeria (Ademiluyi et al., 2008) and 2005 Nigerian settlements database from the National Space Research and Development Agency (NASRDA) (Agbaje \& Fagbeja, 2006). The FORMECU database, which contained only major and minor urban settlements, was created using a combination of satellite sensor images. The satellite sensor data used were Landsat Multispectral Scanner (MSS) for 1976-78; SPOT Multispectral Scanner for 1993-95; Landsat Thematic Mapper (TM) for 1993; ERS-1 Radar for 1994-95; JERS-1 Radar for 1995; and National Oceanic and Atmospheric Administration (NOAA) Advanced Very High Resolution Radiometer (AVHRR) for 1978, 1986, 1990 and 1995 (Ademiluyi et al., 2008). The settlement database from NASRDA was developed using a combination of Landsat Enhanced Thematic Mapper (ETM+) for 2000-04 and NigeriaSat-1 for 2004-05. The satellite sensor data were acquired on different days in order to obtain cloud-free images of Nigeria (Agbaje \& Fagbeja, 2006). According to Agbaje and Fagbeja (2006), the identification of the settlements in the NASRDA database relied on place name datasets generated by the Office of the Surveyor General of the Federation in 1964 and the Federal Ministry of Agriculture through the national Agricultural Development Programme (ADP) as well as an extensive field verification exercise. The two databases were overlaid to update the sizes, names and classes of settlements, considering growth in the spatial extents of settlements estimated at 5.8\% over 3 decades (Alkali, 2005). Consequently, the more recent GIS database available from NASRDA was used to update the size of urban and semi-urban settlements from the FORMECU database, and also to incorporate rural settlements. This produced a more detailed and updated settlements database, with the limits of the areas covered by urban, semi-urban and rural settlements clearly established. The new database (or Niger Delta inventory settlement database) contains all the semi-urban and urban settlements in the Niger Delta. In all, the new database contains 6,715 settlements (Figure 3).

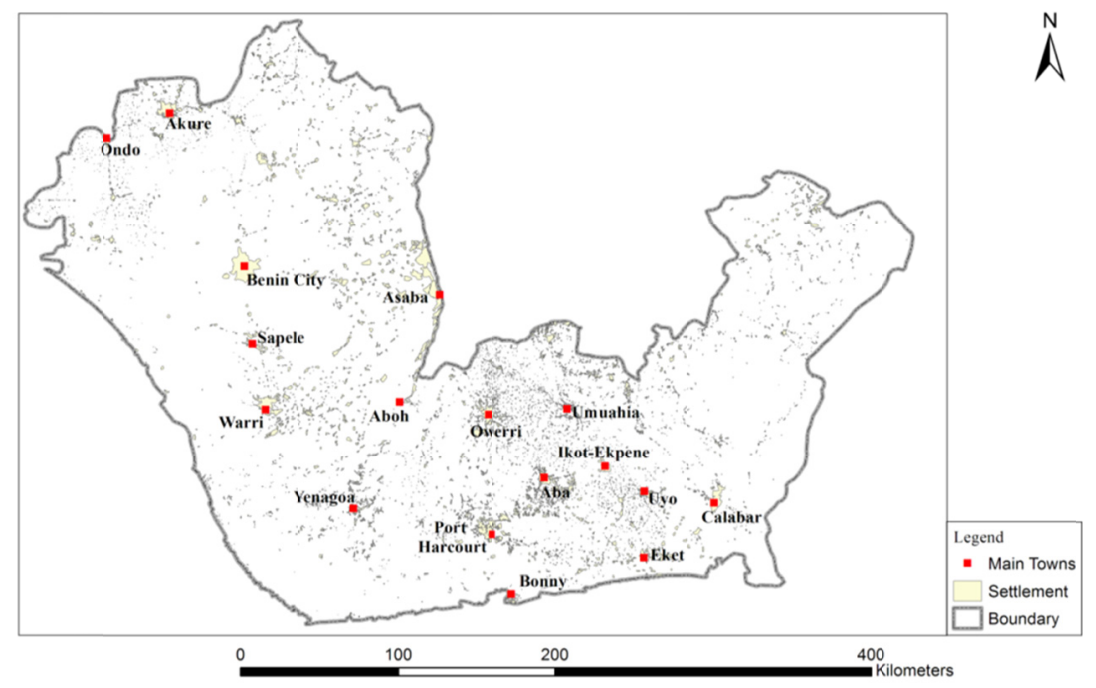

Figure 3. Map showing 6,715 settlements identified in the Niger Delta 


\subsection{Population Estimation}

The settlements in the new database were classified into urban (population above 20,000), semi-urban (population between 5,000 and 20,000) and rural (population below 5,000) based on the population classification of the Niger Delta Regional Development Plan (NDDC, 2006). The area benchmarks for the settlements were set based on the area limits of the minor and major urban settlements estimated from the FORMECU land use and land cover data (Ademiluyi et al., 2008). Based on personal knowledge of Abak (a semi-urban settlement covering an area approximately $9 \mathrm{~km}^{2}$ ) and Ore (an urban settlement covering an area estimated at $9 \mathrm{~km}^{2}$ ), a more rigorous classification process was carried out in order to refine the upper and lower benchmarks for the semi-urban and urban settlement categories respectively (Table 1).

Table 1. Classification of settlements in the Niger Delta into rural, semi-urban and urban classes based on population range (NDDC, 2006) and settlement area benchmarks

\begin{tabular}{llccc}
\hline Class & Population range & $\begin{array}{c}\text { Lower area } \\
\text { benchmark }\left(\mathbf{k m}^{\mathbf{2}}\right)\end{array}$ & $\begin{array}{c}\text { Upper area } \\
\text { benchmark }\left(\mathbf{k m}^{\mathbf{2}}\right)\end{array}$ & $\begin{array}{c}\text { Number of } \\
\text { Settlements }\end{array}$ \\
\hline Rural & Below 5,000 & 0.0001 & 1.0000 & 6126 \\
Semi-urban & 5,001 to 20,000 & 1.0001 & 9.0000 & 544 \\
Urban & 20,001 and above & 9.0001 & 227.0000 & 44 \\
\hline
\end{tabular}

Population estimates for settlements in the Niger Delta are not available from the Nigerian National Population Commission (NPC). Therefore, population estimates were derived based on assumptions and the most reliable population estimates available for some of the identified settlements within the region. The projected 2010 population estimates for 275 settlements were obtained from World Gazetteer (2010). Population estimates for the remaining settlements in the Niger Delta were derived based on the relationship that exists between settlement built-up (or dwelling) area and the population of settlements, assuming the entire settlement area constitutes dwelling area. The allometric relationship (that between a size of settlement and its population) is considered universal (Narrol, 1962; Tobler, 1969; Wiessner, 1974) and is represented by the equation:

$$
\mathrm{A}=\mathrm{a} * \mathrm{P}^{\mathrm{b}}
$$

Where

$$
\begin{aligned}
& \mathrm{A}=\text { Area of built-up area within a settlement } \\
& \mathrm{a}=\text { Coefficient of proportionality, which depends on the units of area measurements and the building } \\
& \text { and living culture within a settlement (Tobler, 1969). } \\
& \mathrm{P}=\text { Population within a settlement } \\
& \mathrm{b}=\text { Positive exponent, estimated to be } 0.88 \text { (Narrol, 1962; Tobler, 1969). }
\end{aligned}
$$

As there is no coefficient of proportionality derived specifically for the cultures of the Niger Delta, logarithmic relationships (Kvamme, 1997) ${ }^{3}$ were established using the projected 2010 population estimates obtained from the World Gazetteer (2010) for 275 settlements and their corresponding area (Table 2). 
Table 2. Settlement size categories, population estimation equations and mean errors derived from the process of establishing a settlement size-population relationship

\begin{tabular}{|c|c|c|c|c|}
\hline $\begin{array}{c}\text { Settlement } \\
\text { Area Category } \\
\left(\mathbf{k m}^{2}\right)\end{array}$ & $\begin{array}{l}\text { Settlement } \\
\text { Class }\end{array}$ & Equation & $\begin{array}{l}\text { Error } \\
(\%)\end{array}$ & Observations / Remarks \\
\hline $0-0.99$ & Rural & $\begin{array}{c}\text { Population }=592.9 \ln (\text { Area })+ \\
4,625.1\end{array}$ & -24 to 21 & $\begin{array}{c}15 \text { out of } 65 \text { settlements } \\
\text { used }\end{array}$ \\
\hline $1-3.99$ & Semi-urban & $\begin{array}{c}\text { Population }=6,966.9 \ln (\text { Area })+ \\
5,300.2\end{array}$ & -27 to 50 & $\begin{array}{c}44 \text { out of } 74 \text { settlements } \\
\text { used }\end{array}$ \\
\hline $4-9.99$ & Semi-urban & $\begin{array}{c}\text { Population }=5,755 \ln (\text { Area })+ \\
3,003.5\end{array}$ & -26 to 56 & $\begin{array}{c}12 \text { out of } 17 \text { settlements } \\
\text { used }\end{array}$ \\
\hline $10-19.99$ & Urban & $\begin{array}{c}\text { Population }=139,445 \ln (\text { Area })- \\
273,706\end{array}$ & - 30 to 38 & $\begin{array}{c}11 \text { out of } 12 \text { settlements } \\
\text { used }\end{array}$ \\
\hline $20-49.99$ & Urban & $\begin{array}{c}\text { Population }=263,324 \ln (\text { Area })- \\
700,463\end{array}$ & -2 to 47 & 4 out of 6 settlements used \\
\hline $50-99.99$ & Urban & - & - & $\begin{array}{l}\text { Population of all the } \\
\text { settlements are known }\end{array}$ \\
\hline 100 - above & Urban & - & - & $\begin{array}{l}\text { Population of all the } \\
\text { settlements are known }\end{array}$ \\
\hline
\end{tabular}

Settlements were excluded from the assessment if their population estimates did not correspond with the area banding indicated in Table 1. Additional criteria were applied to select the settlements used for the generation of logarithmic relationships in order to reduce the error in the population estimation process. Population densities were generated for each settlement category. From this, the average population density was calculated. Furthermore, the percentage difference between the population density of the settlements and the average population density for each category was computed. All the settlements with a percentage difference greater than $50 \%$ were excluded from the estimation process. The scatter plots of population and settlement area for each areal category were used to generate logarithmic relationships for each category. The population of all the other settlements in the database were estimated by applying the appropriate logarithmic equation. However, the settlements with known populations retained their known populations in the final database.

\subsection{Emission Factors}

The emission factors used in this study were selected from available emission factors developed for regions with cooking cultures and fuel composition similar to the Niger Delta. Generalised emission factors for fuel wood and charcoal developed for the West African region were adopted (Brocard et al., 1998). In addition, emission factors developed by Zhang and Morawska (2002) for $\mathrm{PM}_{10}$ emissions from wood and coal combustion in cooking stoves used in China were also adopted. Emission factors for kerosene combustion in wick stoves and natural gas combustion from the Chinese emission factors database (Zhang et al., 2000) were adopted for burning of kerosene and natural gas for cooking. Emission factors for the use of petrol-fuelled generators available from the US Environmental Protection Agency (USEPA) AP-42 Emissions database were adopted (USEPA, 1996). The emission factors used are shown in Table 3. 
Table 3. Compilation of emission factors adopted for domestic cooking and lighting activities in the Niger Delta

\begin{tabular}{|c|c|c|c|}
\hline Activity & Pollutant & Emission Factors & Data source \\
\hline \multirow[t]{5}{*}{ Cooking - Fuel wood } & $\mathrm{CO}$ & $30 \mathrm{~g} \mathrm{C} / \mathrm{kg}$ dry fuel & Brocard et al., 1998 \\
\hline & $\mathrm{CO}_{2}$ & $400 \mathrm{~g} \mathrm{C} / \mathrm{kg}$ dry fuel & Brocard et al., 1998 \\
\hline & $\mathrm{CH}_{4}$ & $1.5 \mathrm{~g} \mathrm{C} / \mathrm{kg}$ dry fuel & Brocard et al., 1998 \\
\hline & $\mathrm{NO}_{\mathrm{x}}$ & $0.7 \mathrm{~g} \mathrm{~N} / \mathrm{kg}$ dry fuel & Brocard et al., 1998 \\
\hline & $\mathrm{PM}_{10}$ & $3.82 \mathrm{~g} / \mathrm{kg}$ dry fuel & Zhang and Morawska, 2002 \\
\hline \multirow[t]{5}{*}{ Cooking - Charcoal } & $\mathrm{CO}$ & $25 \mathrm{~g} \mathrm{C} / \mathrm{kg}$ dry fuel & Brocard et al., 1998 \\
\hline & $\mathrm{CO}_{2}$ & $170 \mathrm{~g} \mathrm{C} / \mathrm{kg}$ dry fuel & Brocard et al., 1998 \\
\hline & $\mathrm{CH}_{4}$ & $0.5 \mathrm{~g} \mathrm{C} / \mathrm{kg}$ dry fuel & Brocard et al., 1998 \\
\hline & $\mathrm{NO}_{\mathrm{x}}$ & $0.29 \mathrm{~g} \mathrm{~N} / \mathrm{kg}$ dry fuel & Brocard et al., 1998 \\
\hline & $\mathrm{PM}_{10}$ & $0.829 \mathrm{~g} / \mathrm{kg}$ dry fuel & Zhang \& Morawska, 2002 \\
\hline \multirow[t]{7}{*}{ Cooking - Kerosene } & $\mathrm{CO}$ & $8.7 \mathrm{~g} \mathrm{C} / \mathrm{kg}$ fuel & Zhang et al., 2000 \\
\hline & $\mathrm{CO}_{2}$ & $3120 \mathrm{~g} \mathrm{C} / \mathrm{kg}$ fuel & Zhang et al., 2000 \\
\hline & $\mathrm{CH}_{4}$ & $0.0436 \mathrm{~g} \mathrm{C} / \mathrm{kg}$ fuel & Zhang et al., 2000 \\
\hline & $\mathrm{NO}_{\mathrm{x}}$ & $0.618 \mathrm{~g} \mathrm{~N} / \mathrm{kg}$ fuel & Zhang et al., 2000 \\
\hline & $\mathrm{PM}_{10}$ & $0.134 \mathrm{~g} / \mathrm{kg}$ fuel & Zhang et al., 2000 \\
\hline & $\mathrm{SO}_{2}$ & $0.0331 \mathrm{~g} \mathrm{~S} / \mathrm{kg}$ fuel & Zhang et al., 2000 \\
\hline & VOC & $0.295 \mathrm{~g} \mathrm{C} / \mathrm{kg}$ fuel & Zhang et al., 2000 \\
\hline \multirow[t]{5}{*}{ Cooking - Gas/Electricity } & $\mathrm{CO}$ & $0.236 \mathrm{~g} \mathrm{C} / \mathrm{kg}$ fuel & Zhang et al., 2000 \\
\hline & $\mathrm{CO}_{2}$ & $3440 \mathrm{~g} \mathrm{C} / \mathrm{kg}$ fuel & Zhang et al., 2000 \\
\hline & $\mathrm{NO}_{\mathrm{x}}$ & $2.89 \mathrm{~g} \mathrm{~N} / \mathrm{kg}$ fuel & Zhang et al., 2000 \\
\hline & $\mathrm{PM}_{10}$ & $0.113 \mathrm{~g} / \mathrm{kg}$ fuel & Zhang et al., 2000 \\
\hline & $\mathrm{SO}_{2}$ & $0.0014 \mathrm{~g} \mathrm{~S} / \mathrm{kg}$ fuel & Zhang et al., 2000 \\
\hline \multirow{6}{*}{$\begin{array}{l}\text { Lighting - Petrol Generator } \\
\text { Exhaust }\end{array}$} & $\mathrm{CO}$ & $0.99 \mathrm{lb} / \mathrm{MMBtu}$ & USEPA (1996) \\
\hline & $\mathrm{CO}_{2}$ & 154 lb/MMBtu & USEPA (1996) \\
\hline & $\mathrm{NO}_{\mathrm{x}}$ & $1.63 \mathrm{lb} / \mathrm{MMBtu}$ & USEPA (1996) \\
\hline & $\mathrm{PM}_{10}$ & $0.1 \mathrm{lb} / \mathrm{MMBtu}$ & USEPA (1996) \\
\hline & $\mathrm{SO}_{2}$ & $0.84 \mathrm{lb} / \mathrm{MMBtu}$ & USEPA (1996) \\
\hline & TOC & $2.1 \mathrm{lb} / \mathrm{MMBtu}$ & USEPA (1996) \\
\hline $\begin{array}{l}\text { Lighting - Petrol Generator } \\
\text { Evaporation }\end{array}$ & TOC & $0.09 \mathrm{lb} / \mathrm{MMBtu}$ & USEPA (1996) \\
\hline $\begin{array}{l}\text { Lighting - Petrol Generator } \\
\text { Crankcase }\end{array}$ & TOC & $0.69 \mathrm{lb} / \mathrm{MMBtu}$ & USEPA (1996) \\
\hline $\begin{array}{l}\text { Lighting - Petrol Generator } \\
\text { Refuelling }\end{array}$ & TOC & $0.15 \mathrm{lb} / \mathrm{MMBtu}$ & USEPA (1996) \\
\hline
\end{tabular}

\subsection{Assumptions}

The series of assumptions used to support the construction of the residential-source inventory and the generation of input data were:

(1) Domestic activities that release air pollutants in the Niger Delta were limited to cooking (using firewood, charcoal, kerosene, gas and electricity) and domestic lighting using petrol engines. Other domestic activities that release air pollutants, but have not been considered in this inventory, are domestic lighting using kerosene lanterns, oil lamps and candles; 
(2) Using population figures as a proxy for estimating emissions assumed that energy use is uniform over a political unit (Marland et al., 1985);

(3) Fuel mix is constant throughout the entire Niger Delta region (Marland et al., 1985). For example, households that use generators for electricity generation use petrol-fuelled generators for an average of four hours a day (from $6 \mathrm{pm}$ to $10 \mathrm{pm}$ );

(4) Domestic cooking is carried out two times a day on weekdays and three times a day on weekends in both the rural and urban areas based on the assumption that during the weekday, people are generally at work and they do not prepare lunch at home. The duration of cooking was assumed to be 1 hour for every cooking session. In a week, it was assumed that cooking activities take place for 16 hours in each household. This assumption was made arbitrarily;

(5) Anozie et al. (2007) estimated the daily energy consumption for cooking in Nigeria per household by combining an estimated daily household energy demand with an assumption of the percentage of this demand expended on cooking. Based on this, the estimated energy consumption for cooking was divided by the average number of hours expended on cooking daily in order to estimate the hourly activity rates (Table 4).

Table 4. Daily cooking energy consumption in Nigeria and average hourly consumption rate assumed for the construction of emissions inventory infrastructure for the Niger Delta

\begin{tabular}{lcc}
\hline \multicolumn{1}{c}{ Cooking fuel } & $\begin{array}{c}\text { Estimated daily consumption } \\
\text { per household (kg) }\end{array}$ & $\begin{array}{c}\text { Estimated hourly consumption per } \\
\text { household (kg) }^{\mathbf{a}}\end{array}$ \\
\hline Fuel wood & 0.8344 & 0.3651 \\
Charcoal & 0.8344 & 0.3651 \\
Kerosene & 0.3981 & 0.1742 \\
Cooking gas / Electricity & 0.0600 & 0.0263 \\
\hline
\end{tabular}

${ }^{a}$ Hourly consumption estimate was based on the assumption that cooking is carried out for 16 hours in a 7 -day week.

Source of National estimate: Anozie et al. (2007); hourly consumption estimate assumed by Fagbeja Mofoluso.

(6) The average household size in the Niger Delta was assumed to be 8 persons for households in rural settlements and 6 persons for households in semi-urban and urban settlements. This assumption was based on the average household size specified by NDDC (2006) in the Niger Delta Regional Development Plan.

(7) The number of households in each settlement was calculated by dividing the estimated population of each settlement with the corresponding household size. This calculation produced estimates of the total number of households in each State (Table 5). Although estimated total number of households for each State of the Niger Delta is available from NBS (2009), the estimates have not been disaggregated based on settlements. Therefore, the number of households generated by the research process was used in the construction of the emissions inventory.

(8) An estimated percentage of households that rely on various fuels for cooking within the Niger Delta available from NBS (2009) was assumed. The breakdown is as shown in Table 5. 
Table 5. Percentage distribution of households by type of fuel for cooking in the nine States of the Niger Delta in 2007

\begin{tabular}{lccccc}
\hline \multicolumn{1}{c}{ State } & $\begin{array}{c}\text { Estimated no. of households } \\
\text { from emission inventory }\end{array}$ & $\begin{array}{c}\text { Fuel wood } \\
\mathbf{( \% )}\end{array}$ & $\begin{array}{c}\text { Charcoal } \\
\mathbf{( \% )}\end{array}$ & $\begin{array}{c}\text { Kerosene } \\
\mathbf{( \% )}\end{array}$ & $\begin{array}{c}\text { Electricity and gas } \\
(\mathbf{\%})\end{array}$ \\
\hline Abia & $1,850,476$ & 73.6 & 0.0 & 25.8 & 0.7 \\
Akwa-Ibom & 324,465 & 81.0 & 0.4 & 18.3 & 0.2 \\
Bayelsa & 151,394 & 57.6 & 0.2 & 41.3 & 0.9 \\
Cross-River & 247,927 & 79.8 & 0.3 & 19.6 & 0.2 \\
Delta & 238,558 & 76.6 & 0.5 & 21.3 & 1.6 \\
Edo & 146,943 & 78.7 & 0.5 & 18.6 & 2.2 \\
Imo & 416,509 & 85.1 & 0.4 & 13.6 & 0.9 \\
Ondo & 346,924 & 66.7 & 0.3 & 32.6 & 0.4 \\
Rivers & 511,787 & 65.2 & 0.7 & 31.3 & 2.8 \\
Total / Average & $\mathbf{4 , 2 3 4 , 9 8 3}$ & $\mathbf{7 3 . 9}$ & $\mathbf{0 . 4}$ & $\mathbf{2 4 . 4}$ & $\mathbf{1 . 2}$ \\
\hline
\end{tabular}

Source: NBS (2009).

(9) In order to estimate the number of households that rely on generators for electricity generation, an estimated percentage distribution of households by the type of electricity supply in 2007 available from NBS (2009) was assumed (Table 6). The percentages of households that have access to electricity using personal generators were applied to the estimated number of households derived from the emission inventory for each State to estimate emissions from the use of personal generators for domestic lighting.

Table 6. Percentage distribution of households by the type of electricity supply ${ }^{+}$in the nine States of the Niger Delta for 2007

\begin{tabular}{ccccccccc}
\hline State & $\begin{array}{c}\text { PHCN } \\
\text { Only (\%) }\end{array}$ & $\begin{array}{c}\text { RE Only } \\
(\mathbf{\%})\end{array}$ & $\begin{array}{c}\text { PG Only } \\
\mathbf{( \% )}\end{array}$ & $\begin{array}{c}\text { PHCN \& } \\
\text { PG (\%) }\end{array}$ & $\begin{array}{c}\text { RE \& } \\
\text { PG (\%) }\end{array}$ & $\begin{array}{c}\text { Solar } \\
(\mathbf{\%})\end{array}$ & $\begin{array}{c}\text { NA } \\
(\mathbf{\%})\end{array}$ & $\begin{array}{c}\text { Total } \\
\text { PG (\%) }\end{array}$ \\
\hline Abia & 44.5 & 0.1 & 5.9 & 15.2 & 0.5 & 0.0 & 33.8 & 21.6 \\
Akwa-Ibom & 46.3 & 2.7 & 3.3 & 7.6 & 1.9 & 0.0 & 38.3 & 12.8 \\
Bayelsa & 10.3 & 10.1 & 13.3 & 5.8 & 37.8 & 0.5 & 22.2 & 56.9 \\
Cross-River & 54.1 & 0.5 & 3.2 & 1.7 & 3.4 & 0.0 & 37.1 & 8.3 \\
Delta & 62.7 & 0.0 & 2.5 & 3.0 & 1.6 & 0.0 & 30.2 & 7.1 \\
Edo & 80.7 & 0.0 & 1.5 & 0.9 & 0.0 & 0.1 & 16.9 & 2.4 \\
Imo & 68.5 & 1.4 & 5.2 & 4.1 & 0.1 & 0.0 & 20.8 & 9.4 \\
Ondo & 58 & 0.0 & 4.3 & 3.4 & 5.3 & 0.0 & 29.0 & 13.0 \\
Rivers & 24.6 & 7.4 & 16.3 & 4.7 & 10.4 & 0.0 & 36.6 & 31.4 \\
Total / Average & 50.7 & 2.4 & 6.4 & 5.2 & 5.6 & 0.04 & 29.7 & 18.1 \\
\hline
\end{tabular}

${ }^{\mathrm{a}}$ The types of electricity supply identified in Table 5 are PHCN - Power Holding Company of Nigeria (National Grid); RE - Rural Electrification; PG - Personal Generators; Solar - Solar Power; and NA - No Access to Electricity.

Source: NBS (2009).

(10) The use of generators in residential homes in the Niger Delta for domestic lighting was assumed to be the range of $650 \mathrm{~W}$ petrol-fuelled generators, with a 4.2 litre tank capacity. The rate of fuel consumption was assumed to be 0.84 litres per hour (estimated at $0.0308 \mathrm{MMBtu}$ per hour) (Note 1). 
(11) The entire area covered by a settlement is built-up. This is unlikely to be the case and will give rise to overestimation in some (probably much localised) areas and underestimation in others.

\section{Results}

The results generated from the estimation of emissions from the identified settlements in the Niger Delta are presented as maps resolved at $10 \mathrm{~km} \times 10 \mathrm{~km}$ grid resolutions. Figures $4(\mathrm{a}-\mathrm{g})$ show the spatial distribution of $\mathrm{CO}, \mathrm{CO}_{2}, \mathrm{CH}_{4}, \mathrm{NO}_{\mathrm{x}}, \mathrm{PM}_{10}, \mathrm{SO}_{2}$ and VOCs released from settlements in the Niger Delta. The spatial distribution of emissions over the Niger Delta shows that highest rates of emission of pollutants and GHGs from residential sources occur over the urban areas of Aba, Akure, Benin City and Port Harcourt. Other urban and semi-urban areas also record high emission estimates. The majority of these areas are located in the central and northwestern part of the Niger Delta. The results from the inventory show that from domestic cooking and lighting activities in the Niger Delta, the annual estimates generated are $70 \mathrm{kt} \mathrm{yr}^{-1} \mathrm{CO}, 50 \mathrm{kt} \mathrm{yr}^{-1} \mathrm{NO}_{\mathrm{x}}, 3 \mathrm{kt} \mathrm{yr}^{-1} \mathrm{PM}_{10}, 2.4 \mathrm{kt} \mathrm{yr}^{-1} \mathrm{SO}_{2}$, $60 \mathrm{t} \mathrm{yr}^{-1} \mathrm{VOC}, 5.7 \mathrm{mt} \mathrm{yr}^{-1} \mathrm{CO}_{2}$ and $2 \mathrm{kt} \mathrm{yr}^{-1} \mathrm{CH}_{4}$.
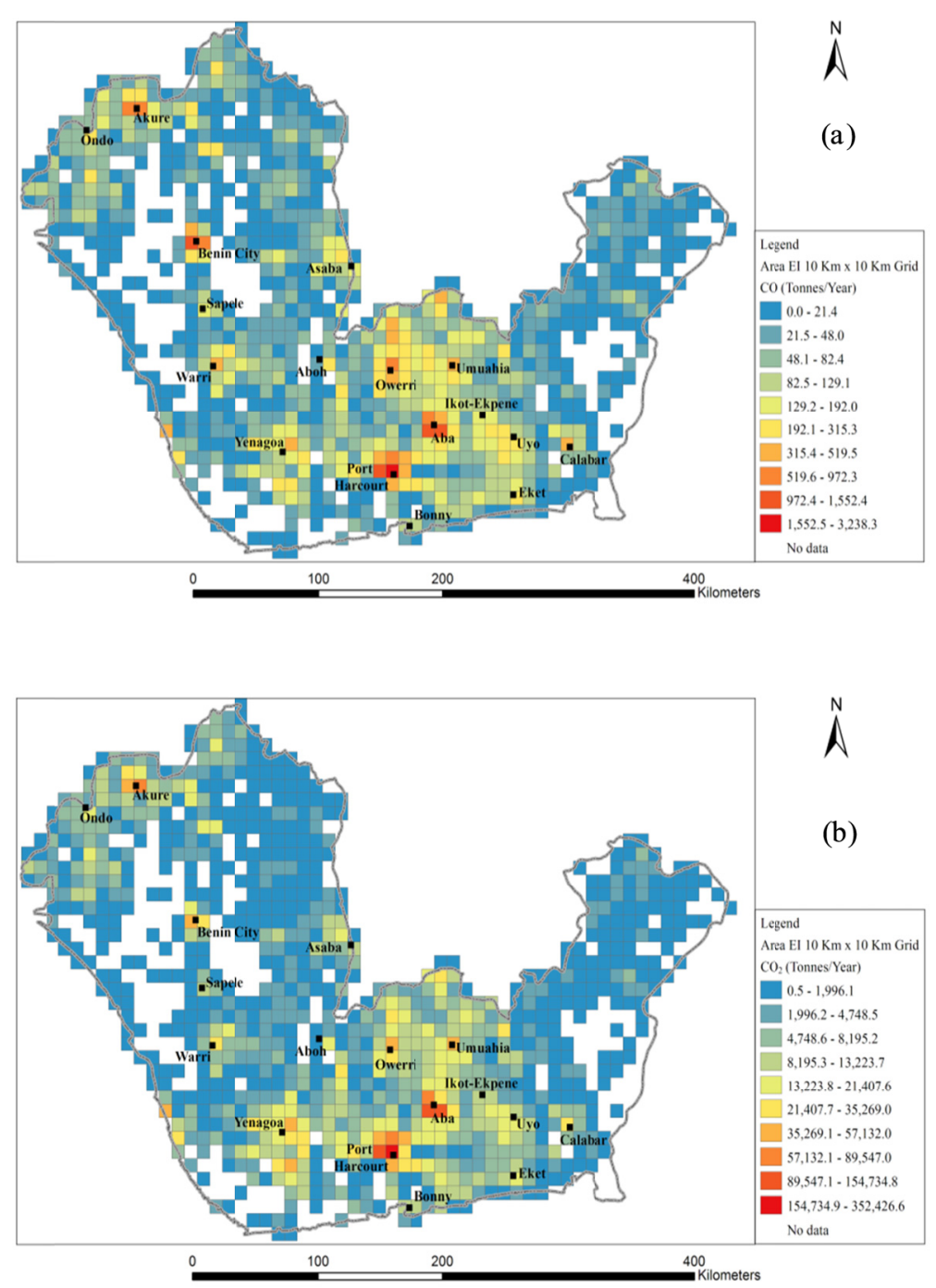

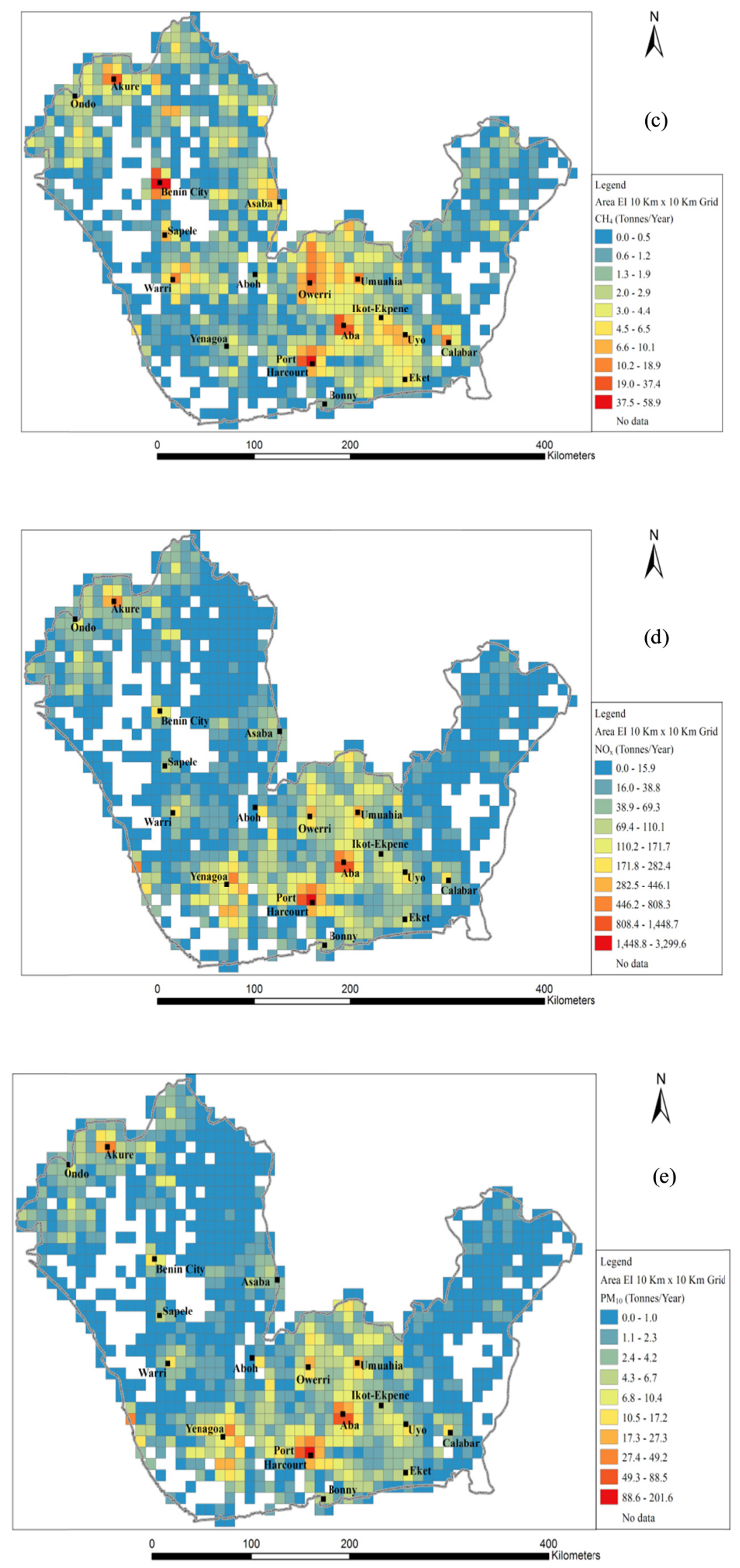

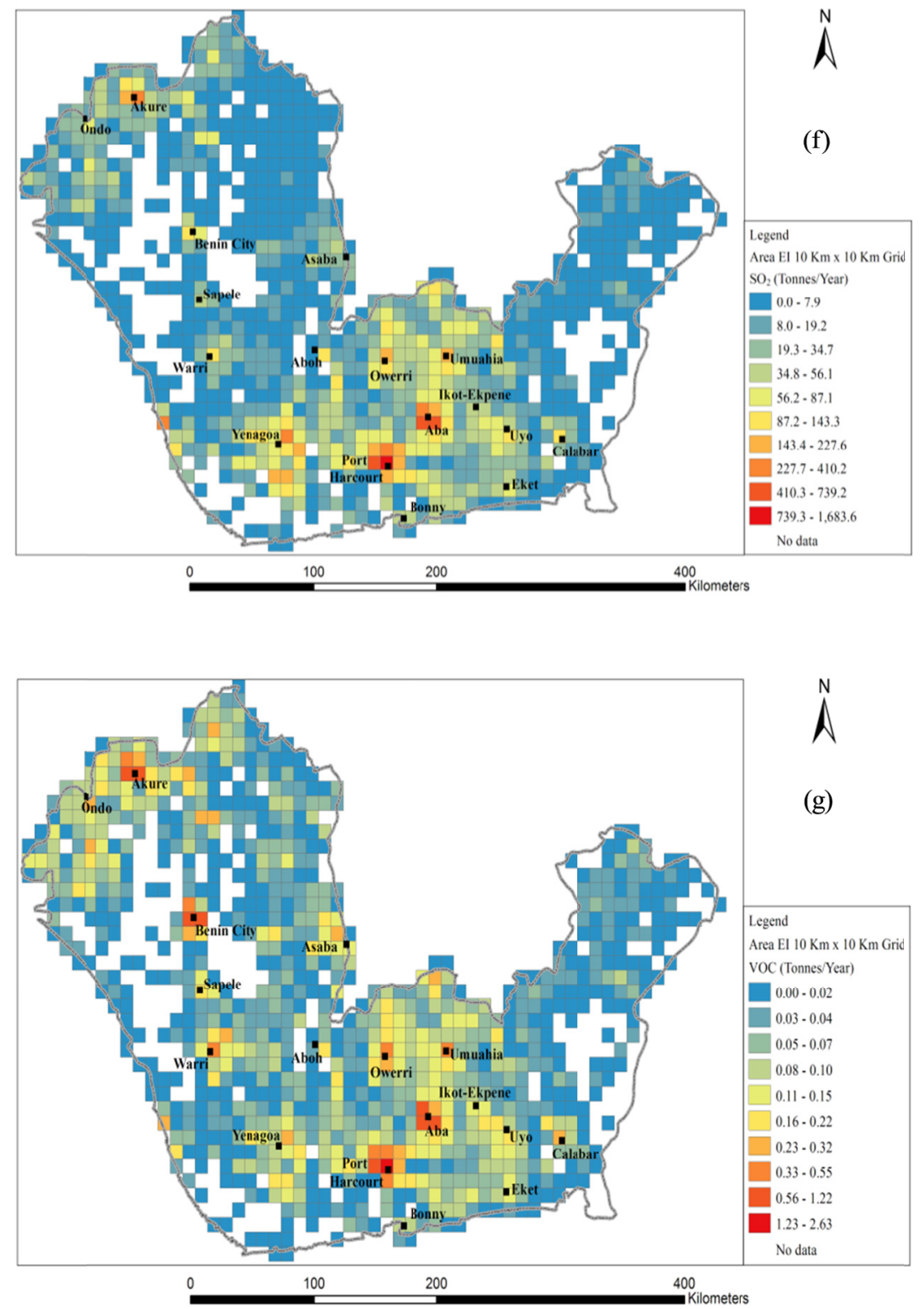

Figure $4.10 \mathrm{~km}$ grid-based emission estimates generated from the settlements in the Niger Delta region of Nigeria. (a) $\mathrm{CO}$, (b) $\mathrm{CO}_{2}$, (c) $\mathrm{CH}_{4}$, (d) $\mathrm{NO}_{\mathrm{x}}$, (e) $\mathrm{PM}_{10}$, (f) $\mathrm{SO}_{2}$, (g) VOC. The unit shown on maps is metric tonnes per year $\left({\left.\mathrm{t} \mathrm{yr}^{-1}\right)}^{-1}\right.$

Figure $5(\mathrm{a}-\mathrm{g})$ shows the contribution of the various cooking and lighting activities considered in this study to emissions of the trace gases. Domestic cooking using firewood and kerosene, and domestic lighting using generators constitute the significant sources of air pollutants in the Niger Delta. Firewood and lighting produced approximately 35,000 and 25,000 tonnes of $\mathrm{CO}$. Lighting produced 4 million tonnes of $\mathrm{CO}_{2}$, while kerosene and firewood produced an estimated 558,000 and 465,000 tonnes of $\mathrm{CO}_{2}$ respectively. 
(a)

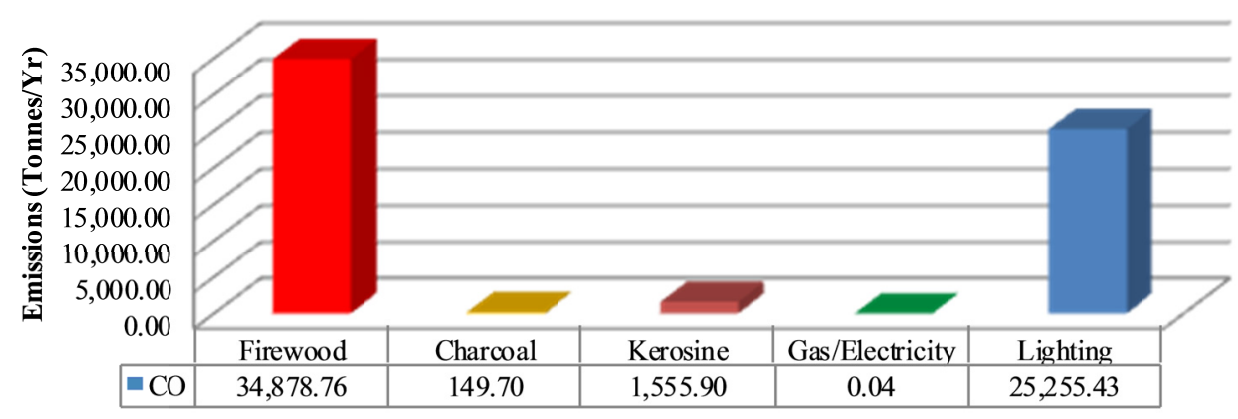

(b)

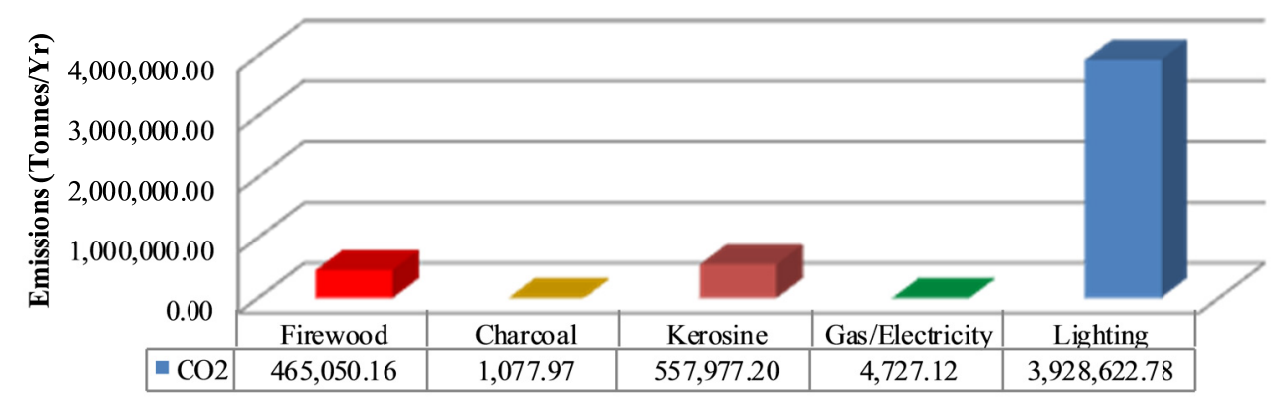

(c)

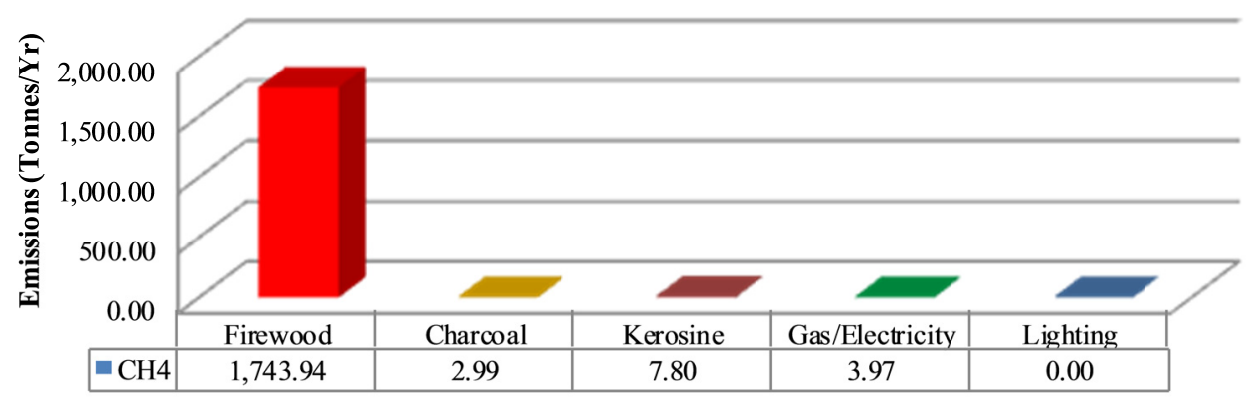

(d)

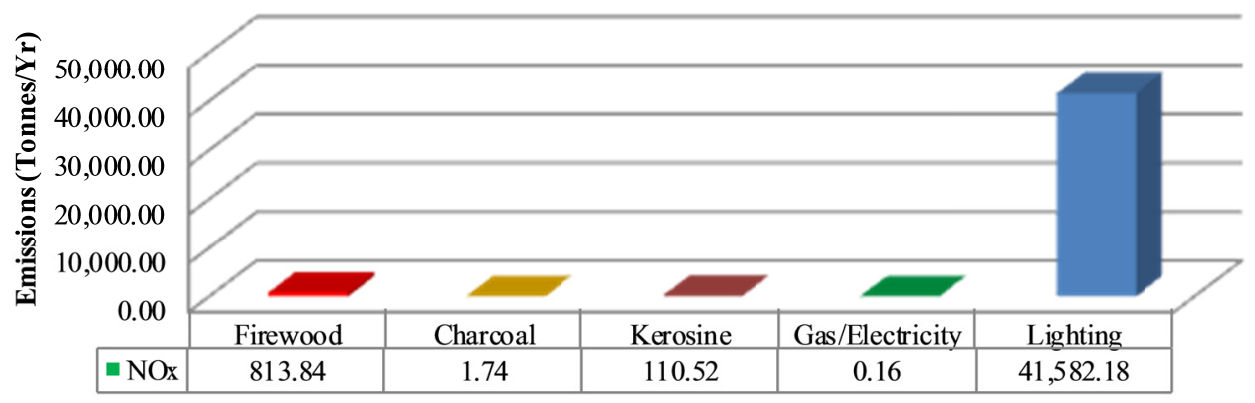


(e)

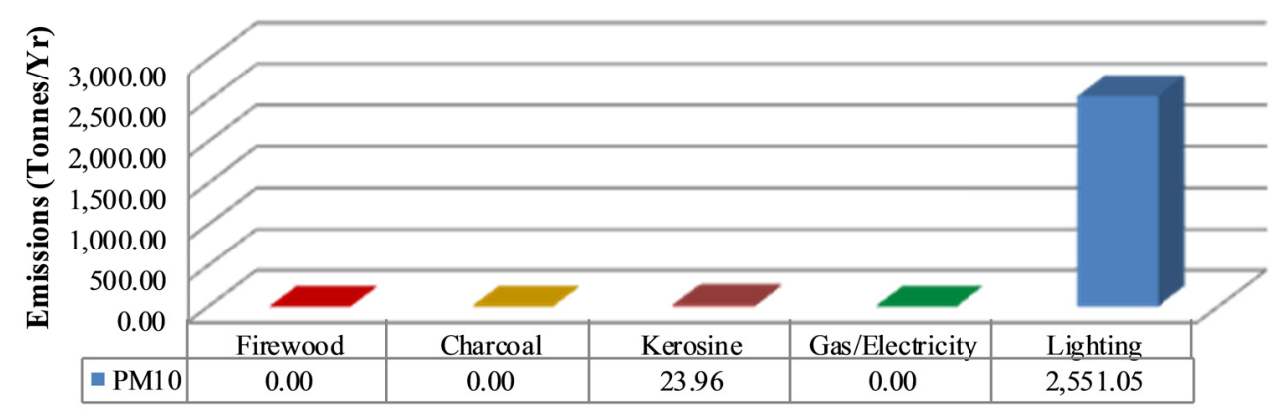

(f)

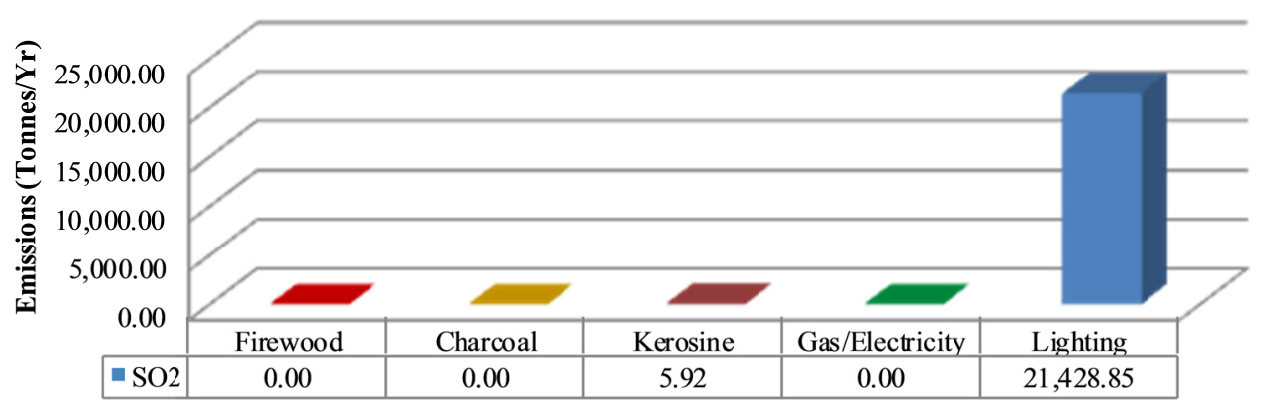

(g)

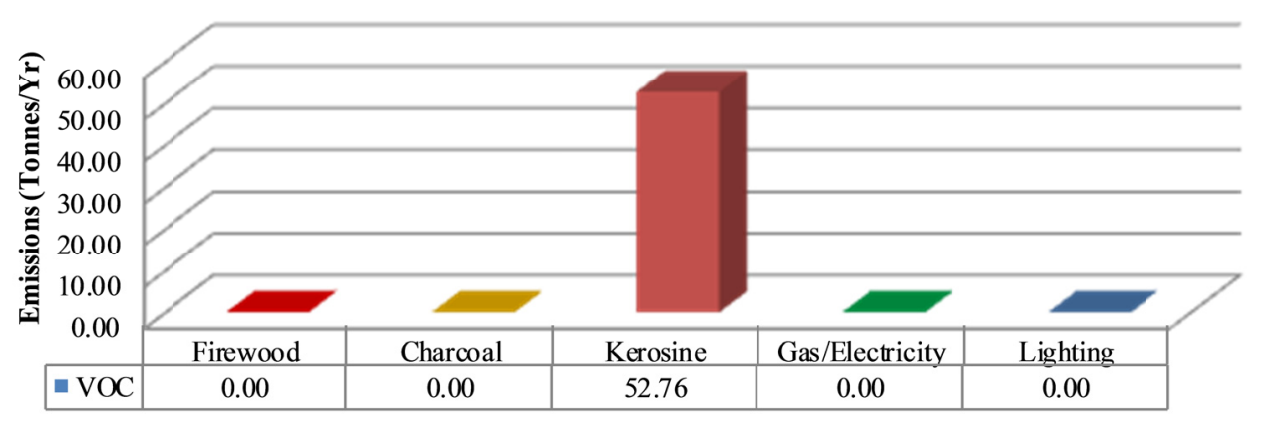

Figure 5. Contribution of domestic cooking and lighting practices to emissions in the Niger Delta. (a) CO, (b) $\mathrm{CO}_{2}$, (c) $\mathrm{CH}_{4}$, (d) $\mathrm{NO}_{\mathrm{x}}$, (e) $\mathrm{PM}_{10}$, (f) $\mathrm{SO}_{2}$, (g) VOC

Based on the population estimation process used for the construction of the inventory, the total population derived from the inventory methodology is estimated at 36,163,712 (as compared to 35.3 million projected for 2010 based on the 2006 census estimates). The disaggregated population estimates for the rural, semi-urban and urban settlement categories are approximately 18.8 million, 4.9 million and 12.5 million respectively. There is a proportional relationship between the emission estimates generated from the inventory and the population. The rural population, which constitutes $52 \%$ of the entire population of the Niger Delta, contributes $51 \%$ to $54 \%$ of the total emissions from domestic activities in the Niger Delta. The urban population, which constitutes $34 \%$ of the population, contributes $33 \%$ to $36 \%$ of the emission estimates. Finally, semi-urban settlements, which constitutes $14 \%$ of the population, produce $13 \%$ to $14 \%$ of the emission estimates generated in the Niger Delta. 


\section{Discussion}

\subsection{Population Estimation}

According to NDDC (2006), there are an estimated 13,329 settlements in the Niger Delta region. However, the input settlement data in the Niger Delta inventory contains 6,715 settlements. NDDC (2006) states that the majority of settlements in the Niger Delta are very small and scattered rural hamlets, fishing or farming settlements, which are located along the riverbanks. The population of these settlements ranges from 50 to 500 persons (NDDC, 2006). The Niger Delta Human Development Report, produced by the United Nations Development Programme in 2006, supports the observation of NDDC (2006) on the number of settlements in the region. According to UNDP (2006), an estimated 7,686 settlements in the Niger Delta have populations that are lower than 1,000. In addition to low population, this class of settlements are small in size (UNDP, 2006). Due to the small size of these settlements, it was difficult to identify them from the medium spatial resolution satellite images used to identify the settlements contained in the emission inventory database (Ademiluyi et al., 2008; Agbaje \& Fagbeja, 2006). Consequently, this study relies on approximately $50 \%$ of the settlements in the Niger Delta. Despite this shortfall in the total number of settlements available for the inventory, it is assumed that all the urban and semi-urban settlements in the Niger Delta are contained in the inventory settlement database (See section 2.1). This assumption is based on the methods and base data available from Agbaje and Fagbeja (2006), which were used to develop the database. Considering the size of the settlements in these categories, it is expected that they would have been captured in the processes of settlement identification. However, it is important to note that there are variations in the settlement category, which some of these urban and semi-urban settlements fall into due to the potential overestimations and underestimations in the method used in this study, as noted in Assumption 11 in Section 2.4. Figure 6 shows a graphical comparison of the number of settlements that fall into a specific population-based category as observed by UNDP (2006) as against those derived from the inventory. According to the comparison in Figure 6, the Niger Delta inventory settlement database records shortfalls of 242 and 28 in the number of settlements in the semi-urban and urban categories respectively. However, the inventory has 1,304 settlements more than number of settlements recorded by UNDP (2006) in the rural category with population range of 1,000 to 5,000 persons. The shortfall of 28 settlements recorded in the urban settlement category (population $>20,000$ ) is assumed to have been accounted for in the semi-urban category (population range of 5,000 to 20,000). Similarly, the shortfall of 270 settlements recorded in the semi-urban category has been accounted for in the rural category (population range of 1,000 to 5,000). At this stage, it is difficult to verify this due to a lack of access to the settlement / population data used for the categorisation documented by UNDP (2006).

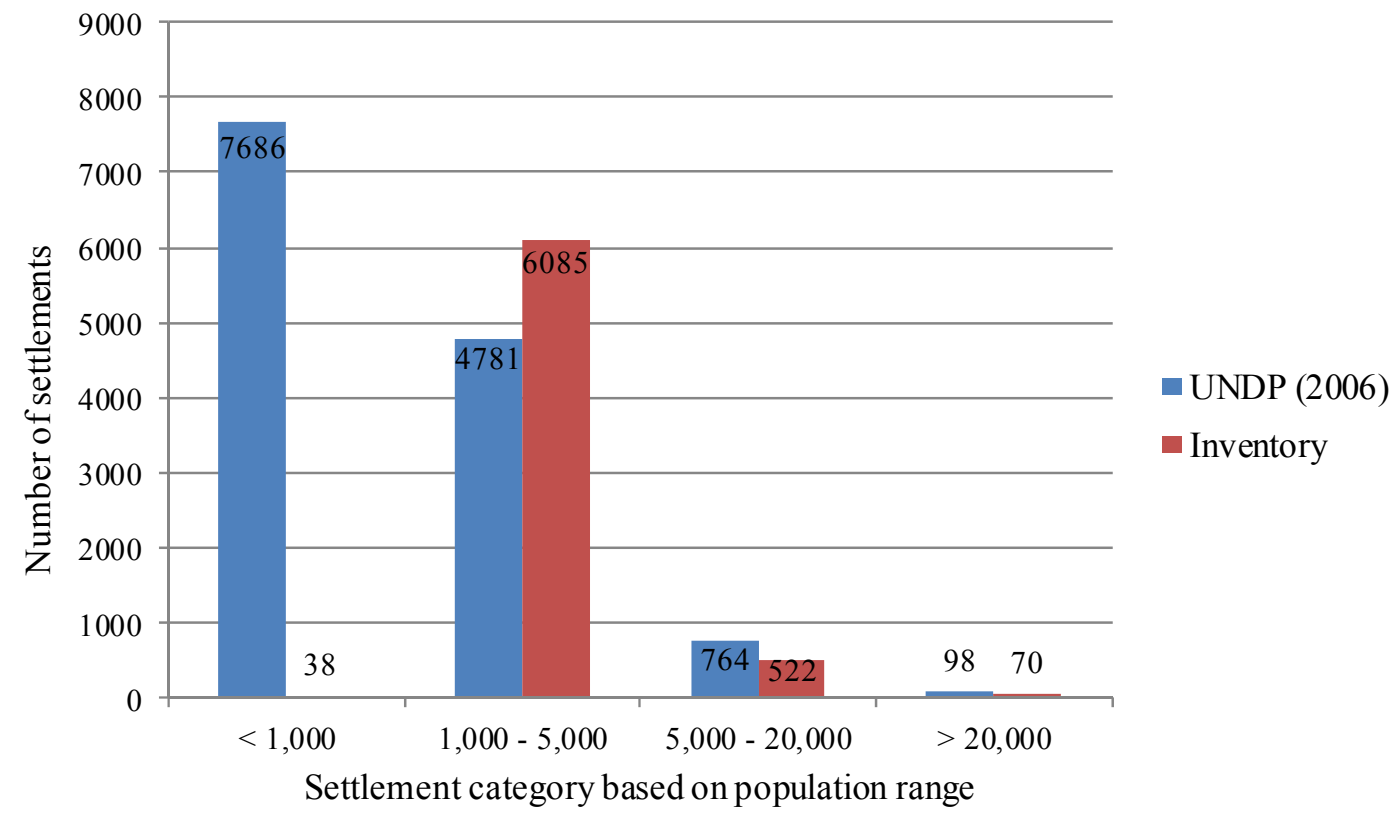

Figure 6. Comparison of the number of settlements within each settlement category as observed by UNDP (2006) against those derived from the Niger Delta inventory 
Following the process of estimating population for the settlements using logarithmic relationships between settlement area and population (Kvamme, 1997) as described in Section 2.2, the derived total population from the settlements contained in the Niger Delta inventory is estimated at $36,163,712$. The derived population is based on the projected 2010 population of some of the settlements within the region (World Gazetteer, 2010). According to the 2006 population census, the total population of the Niger Delta is estimated at 31,224,177 (NBS, 2006a). Considering an estimated annual population growth rate of $3.1 \%$ for the Niger Delta (NDDC, 2006), the estimated 2010 population of the Niger Delta is $35,279,763$. Therefore, the derived population from the inventory is overestimated above the projected 2010 population estimate for the Niger Delta by approximately 3\%. Based on the information contained in Figure 7, the category of settlements that are not included in the Niger Delta inventory database are those with populations considerably less than 1,000. Assuming that each of these 6,614 settlements have populations ranging from 50 to 500 would suggest that a total population range of approximately 330,700 to $3,307,000$ is unaccounted for by the inventory. In addition, knowing the range of population that is unaccounted for, and adding it to the derived population of the Niger Delta, the population estimation method used for this study would have potentially overestimated the population of the Niger Delta by $3 \%$ to $11 \%$. In view of this margin of error likely falling within $10 \%$, the population estimation process used for this study is considered reliable. It may be important to verify the locations and aerial extents of the settlements that are not included in the inventory database in order to improve the population estimation process and the estimates of emissions generated from the region. High spatial resolution satellite images, such as NigeriaSat-2, would assist in achieving this. The identification of these populations may be advantageous not just in terms of estimating emissions but also in assessing exposure to air pollution.

\subsection{Estimates and Spatial Distribution of Emissions from Residential Sources in the Niger Delta}

This sub-section discusses the uncertainties in the spatial distribution of emissions over the Niger Delta and the emission estimates generated from the inventory. In addition, the challenges of verifying the Niger Delta emissions inventory are discussed, considering the source categorisation of emissions and uncertainties in the emission estimates.

\section{a. Uncertainties in spatial distribution of emissions}

The total population estimate for urban and semi-urban settlements in the inventory with known populations from World Gazetteer (2010) is 12,192,311. This constitutes approximately $34 \%$ of the total derived population of the Niger Delta. In addition, approximately 372,240 are distributed amongst the rural settlements with known populations according to World Gazetteer (2010). This constitutes approximately 1\% of the total derived population. Considering the spatial location of $35 \%$ of the population is known, and based on the generalisations involved in this study, it can be inferred that the spatial distribution of approximately $35 \%$ of the emission estimates is likely to be fairly accurate. However, much greater uncertainty is introduced by the assumption that the entire area covered by a settlement is built up. Consequently, there is likely to be a large, though unquantifiable, uncertainty in the spatial distribution of emissions generated from settlements in the Niger Delta. The uncertainty is large due to the level of generalisation in the input data and it is unquantifiable due to lack of comparable data. Consequently, the spatial distribution of the emissions generated from settlements is only accurate to the extent of the accuracy of the distribution of population within settlements, which is currently unquantifiable.

The uncertainties involved in this inventory may reduce and become quantifiable as and when potentially accurate and appropriately disaggregated data are available. However, the methodology used in this study verifies the functionality of the inventory to produce accurate results as and when appropriate data are available. It is worth noting that the results generated from the inventory (Figure 5) appear to have a correlation with the spatial distribution of the population density of the Niger Delta (Figure 2). The spatial distribution of emissions of pollutants and GHGs considered in this study shows considerable emissions generated over areas with population densities greater than 225 persons per $\mathrm{km}^{2}$. Such areas include the urban and semi-urban areas and some coastal rural settlements. This further underscores the strength of the methodology and its transferability.

b. Uncertainties in the emission estimates generated from the inventory

The emission factors used for this estimation process (Brocard et al., 1998; Zhang et al., 2000; Zhang \& Morawska, 2002; USEPA, 1996) are generalised and have not been specifically developed for the Niger Delta, but they are the available appropriate factors considering the similarity in the cooking and lighting practices they represent. The application of out-of-date and generalised emission factors for this study is an indication of the need to develop emission factors specific to activities within developing regions and to conduct emission estimation studies for these developing regions. The majority of the activity data used are generated on the basis 
of assumptions, and available proxy information are aggregates based on estimates generated at national, regional and individual States level. For example, the value used for daily energy consumption through cooking is based on national estimates. In addition, the rural and urban household sizes applied to all the States are the average regional estimates available for the entire region. There may be some, but not considerable, variations in the national, regional and local criteria applied. Therefore, these may further introduce some uncertainties in the estimates generated, which are based on the number of households.

According to Gordon (2005), there are an estimated 146 languages or ethnic groups in the Niger Delta. This may be an indication of variations in cultural and socio-economic practices, which may also have a bearing on domestic activities among the various ethnic groups in the region. In view of this, the use of input data aggregated at the State level introduces uncertainties into the emission estimates generated from the inventory. A further disaggregation based on Local Government Areas or settlements is expected to produce estimates that give better representations of the local rates of emission from residential sources within individual settlements. Additional uncertainties are introduced through the assumptions on daily fuel use, which did not take into consideration variations in domestic behaviours and fuel consumption between urban and rural dwellers. The availability of such disaggregated data may also enhance the robustness of the inventory infrastructure. In view of the unavailability of location-specific information of household distributions, it may be desirable, as data become available, to verify the effect on emission estimates of location-specific information concerning household distributions as against the assumption that entire settlement area is built-up and households are evenly distributed across settlement area.

\subsection{Relevance of Infrastructure to Policy Development of an Air Quality Management Framework in Nigeria}

As a critical component of an air quality management framework, an emission inventory must generate accurate emission estimates to provide the input data for modelling the dispersion of pollutants, which help in assessing exposures of humans and environment to the risks resulting from the pollution. The main purpose of focusing on publicly available data for the construction of the inventory presented in this paper is to identify existing gaps in data required to generate accurate estimates of emissions air pollutants and GHGs from domestic cooking and lighting activities in a developing country, Nigeria, as exemplified by the Niger Delta. The strength of an air quality management framework depends on environmental regulations and reporting (Murrells et al., 2009), which is currently unavailable in the majority of developing countries, including Nigeria. The absence of the regulations and reporting mechanisms in most developing countries informs their lack of effective air quality management frameworks. It further underscores the limitations encountered by this study in the availability and access to the required data for the Niger Delta. In addition to the identification of existing data gaps, the relevance of this study to aid the development of an air quality management framework lies in the availability and functionality of the infrastructure. The infrastructure is the first spatially-enabled inventory infrastructure developed in sub-Saharan Africa. The techniques presented in this paper could be replicated for other parts of Nigeria in order to extend the scope of the inventory to the entire country. The scope and methodology are also relevant to other developing countries currently without functional and verifiable inventories. The areas that require priority attention in further development of the infrastructure and improving its relevance towards the development of a national air quality management framework are:

(1) Verification of the number of settlements within the Niger Delta by acquiring high-resolution satellite images to identify and map all the settlements currently not available on the inventory database. The availability of high-resolution NigeriaSat-2 satellite from NASRDA shall be invaluable in achieving this.

(2) Provision of population and other demographic estimates for each settlement within the region by the National Population.

(3) Further disaggregated statistical data on rates of fuel consumption for domestic cooking and lighting to settlements and / or local government area levels.

(4) Collaboration with universities and research institutions to develop localised emission factors for fuel consumption.

The Nigerian National Environmental Standards and Regulations enforcement Agency (NESREA), being the main environmental management agency in Nigeria, should collaborate with relevant organisations to develop robust mechanisms through which relevant agencies collect, analyse and publicly provide data appropriately disaggregated into formats that are relevant to estimating emissions from residential activities in Nigeria. Similar agencies in developing countries could adopt these recommended strategies. 


\section{Conclusion and Recommendations}

This residential-source emission inventory infrastructure for the Niger Delta is a critical development that will assist air quality and carbon emission specialists in Nigeria to generate reliable emission estimates and produce maps of the spatial distribution of emissions of air pollutants and GHGs from residential activities. The inventory relies on the capabilities and inter-operability of GIS and spreadsheet applications. Its visual display will assist policy makers to appreciate the air quality scenario in the region, thereby enabling them to develop and test appropriate policies and legislation to improve the quality of air and reduce carbon dioxide emissions in the Niger Delta. The inventory also constitutes a component of the GIS-based Niger Delta Emission Inventory (NDEI) infrastructure, which has been designed and constructed to estimate emissions from a much wider range of point, line and area sources identified in the Niger Delta. The process undertaken in this study has identified the gaps in data requirements that currently exist in the Niger Delta.

The results generated from the inventory currently indicate varying degrees of accuracy and uncertainty arising from generalisation, incomplete spatial data and input data with limited accuracy. Although the inventory provides emission estimates on an annual basis, the activities that release emissions are assessed based on hourly rates of emission release. However, the best available input data make gross generalisations about the hourly rates of activities. Consequently, a further refinement of the input data will be required to reduce the level of generalisation by establishing the more specific hourly rates of activities and energy consumption during cooking and lighting. This can then form the basis for daily energy consumption rates from which annual emission estimates could be generated. In order to improve on the accuracy of emission estimates, this study recommends the conduct of a pilot survey in order to gather site-specific information, which will serve as input data into the inventory. This may be conducted in collaboration with the Nigerian National Environmental Standards Regulations and Enforcement Agency (NESREA). In addition, an investigation into the spatial distribution of households within settlements will further enhance the accuracy that might result from better spatially resolved data. The availability of high-resolution satellite sensor observations at the National Space Research and Development Agency (NASRDA) may be invaluable in achieving this. This paper further recommends that the Nigerian National Population Commission should collate and make available population and demographic estimates for all settlements in the country.

Accurate estimates of emissions released from residential sources are important for health-risk assessment, which stands to enhance knowledge-based decision-making. This study provides an indicator to NESREA of the areas of data acquisition required to enhance their development of an air quality management framework for Nigeria.

The methodology for the construction of the inventory is relevant and transferrable to other developing regions to produce spatially-enabled inventories. The use of assumptions to support publicly available data can be applied to other developing regions with data limitations similar to the Niger Delta. The relevant agencies in these countries may adopt the recommendations of this study in order to improve on their emission estimation processes.

\section{Acknowledgement}

The authors acknowledge the financial support of the National Space Research and Development Agency (NASRDA) and the University of the West of England, Bristol.

\section{References}

Ademiluyi, A. I., Okude, A. S., \& Akanni, C. O. (2008). An appraisal of land use and land cover mapping in Nigeria. African Journal of Agricultural Research, 3, 581-586.

Agbaje, G. I., \& Fagbeja, M. (2006). Creation of the national geo-spatial data infrastructure (NGDI) fundamental datasets from medium-resolution satellite imagery - NigeriaSat-1 for sustainable national development. AARSE $6^{\text {th }}$ International Conference, Cairo 2006.

Alkali, J. L. S. (2005). Planning sustainable urban growth in Nigeria: challenges and strategies, in: Anon., Planning and Urban Growth and Sustainable Architecture. ECOSOC Chambers, United Nations Headquarters, New York. Retrieved June 6, 2005, from http://www.un.org/docs/ecosoc/meetings/2005/docs/Alkali.pdf

Alves, C., Goncalves, C., Fernandes, A. P., Tarelho, L., \& Pio, C. (2011). Fireplace and woodstove fine particle emissions from combustion of western Mediterranean wood types. Atmospheric Research, 101, 692700. http://dx.doi.org/10.1016/j.atmosres.2011.04.015 
Anozie, A. N., Bakare, A. R., Sonibare, J. A., \& Oyebisi, T. O. (2007). Evaluation of cooking energy cost, efficiency, impact on air pollution and policy in Nigeria. Energy, 32, 1283-1290. http://dx.doi.org/10.1016/j.energy.2006.07.004

Banerjee, T., Barman, S. C., \& Srivastava, R. K. (2011). Application of air pollution dispersion modelling for source- contribution assessment and model performance evaluation at integrated industrial estate-Pantnagar. Environmental Pollution, 159, 865-875. http://dx.doi.org/10.1016/j.envpol.2010.12.026

Behera, S. N., Sharma, M., Dikshit, O., \& Shukla, S. P. (2011). GIS-based emission inventory, dispersion modelling, and assessment for source contributions of particulate matter in an urban environment. Water Air Soil Pollution, 218, 423-436. http://dx.doi.org/10.1007/s11270-010-0656-x

Brocard, D., Lacaux, J., \& Eva, H. (1998). Domestic biomass combustion and associated atmospheric emissions in West Africa. Global Biochemical Cycles, 12, 127-139. http://dx.doi.org/10.1029/97GB02269

Department for Environmental Affairs and Tourism (DEAT). (2007). The 2007 national framework for air quality management in the Republic of South Africa. DEAT, South Africa.

Department for Environmental Affairs and Tourism (DEAT). (2008). Manual for air quality management planning in South Africa. Zanokuhle Environmental Services, Overport, South Africa.

De Kluizenaar, Y., Aherne, J., \& Farrell, E. P. (2001). Modelling the spatial distribution of $\mathrm{SO}_{2}$ and $\mathrm{NO}_{x}$

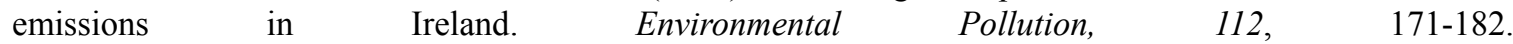
http://dx.doi.org/10.1016/S0269-7491(00)00120-2

Duduta, N., \& Bishins, A. (2010). Citywide transportation greenhouse gas emissions inventories: a review of selected methodologies. WRI Working Paper. World Resource Institute, Washington, DC.

European Commission, Joint Research Centre (JRC) / Netherlands Environmental Assessment Agency (PBL). (2010). Emission database for global atmospheric research (EDGAR). Release version 4.1. Retrieved from http://edgar.jrc.ec.europa.eu

Gordon, R. G. (2005). Ethnologue: Languages of the World. Fifteenth Edition. SIL International.

Hicks, F. J. (1998). Enhancing the productivity of urban Africa. International Conference on Research Community for the Habitat Agenda Forum of Researchers on Human Settlements. Geneva., July 6-8, 1998.

Kvamme, K. L. (1997). A wider view of the relationship between settlement size and population in the Peruvian Andes. American Antiquity, 62, 719-722. http://dx.doi.org/10.2307/281890

Lim, B., Boileau, P., Bonduki, Y., van Amstel, A. R., Janssen, L. H. J. M., Olivier, J. G. J., \& Kroeze, C. (1999). Improving the quality of national greenhouse gas inventories. Environmental Science and Policy, 2, 335-346. http://dx.doi.org/10.1016/S1462-9011(99)00023-4

Lindley, S. J., Longhurst, J. W. S., Watson, A. F. R., \& Conlan, D. E. (1996). Procedures for the estimation of regional scale atmospheric emissions - An example from the North West Region of England. Atmospheric Environment, 30, 3079-3091. http://dx.doi.org/10.1016/1352-2310(95)00304-5

MacCarthy, J., Li, Y., Murrells, T. P., Okamura, S., Passant, N., Sneddon, S., Martinez, C., ... Misselbrook, T. (2010). Air Quality Pollutant Inventories for England, Scotland, Wales and Northern Ireland: 1990 - 2008. National Atmospheric Emissions Inventory, AEA Group, Oxfordshire, UK.

Marland, G., Rotty, R. M., \& Treat, N. L. (1985). $\mathrm{CO}_{2}$ from fossil fuel burning: global distribution of emissions. Tellus, B(37B), 243-258. http://dx.doi.org/10.1111/j.1600-0889.1985.tb00073.x

Murrells, T. P., Passant, N. R., Thistlewaite, G., Wagner, A., Li, Y., Bush, T., ... Brophy, N. (2011). UK emissions of air pollutants 1970-2009. AEA, Harwell, Oxfordshire, UK.

Naroll, R. (1962). Floor area and settlement population. American Antiquity, 27, 587-588. http://dx.doi.org/10.2307/277689

National Bureau of Statistics (NBS). (2005). Poverty profile for Nigeria. National Bureau of Statistics, Abuja, Nigeria.

National Bureau of Statistics (NBS). (2006a). Federal Republic of Nigeria: 2006 Population Figures. National Bureau of Statistics, Abuja, Nigeria.

National Bureau of Statistics (NBS). (2006b). The Nigerian Statistical Fact Sheets on Economic and Social Development. National Bureau of Statistics, Abuja, Nigeria. 
National Bureau of Statistics (NBS). (2009). Social Statistics in Nigeria. National Bureau of Statistics, Abuja, Nigeria.

Niger Delta Development Commission (NDDC). (2006). Niger Delta Development Regional Master Plan. Niger Delta Development Commission, Port Harcourt, Nigeria.

Olivier, J. G. J., Berdowski, J. J. M., Peters, J. A. H. W., Bakker, J., Visschedijk, A. J. H., \& Bloos, J. J. (2001). Applications of EDGAR including a description of EDGAR 3.2: reference database with trend data for 1970-1995. National Institute for Public Health and the Environment (RIVM), Bilthoven, Netherlands.

Onyeka, E. C. (2006). Relating the Nigerian reference frame and AFREF. $5^{\text {th }}$ FIG Regional Conference, Accra Ghana, 8 - 11 March 2006.

Parra, R., Jimenez, P., \& Baldasano, J. M. (2006). Development of the high spatial resolution EMICAT2000 emission model for air pollutants from the north-eastern Iberian Peninsula (Catalonia, Spain). Environmental Pollution, 140, 200-219. http://dx.doi.org/10.1016/j.envpol.2005.07.021

Pastorello, C., Caserini, S., Galante, S., Dilara, P., \& Galletti, F. (2011). Importance of activity data for improving the residential wood combustion emission inventory at regional level. Atmospheric Environment, 45, 2869-2876. http://dx.doi.org/10.1016/j.atmosenv.2011.02.070

Streets, D. G., Bond, T. C., Carmichael, G. R., Fernandes, S. D., Fu, Q., He, D., Kilmont, Z., ... Yarber, K. F. (2003). An inventory of gaseous and primary aerosol emissions in Asia in the year 2000. Journal of Geophysical Research, 108(D21), 8809. http://dx.doi.org/10.1029/2002JD003093

Su, S., Li, B., Cui, S., \& Tao, S. (2011). Sulphur dioxide emissions from combustion in China: from 1990 to 2007. Environmental Science and Technology, 45, 8403-8410. http://dx.doi.org/10.1021/es201656f

Tobler, W. (1969). Satellite confirmation of settlement size coefficients. Area I, 30-34.

Ukoli, M. K. (2001). Environmental Factors in the Management of the Oil and Gas Industry in Nigeria. Central Bank of Nigeria, Abuja, Nigeria.

United Nations Development Programme (UNDP). (2006). Niger Delta Human Development Report. United Nations Development Programme, Abuja, Nigeria.

United Nations Development Programme (UNDP). (2007). UNDP Human Development Report 2007/2008 Fighting Climate Change: Human Solidarity in a Divided World. United Nations Development Programme, New York.

United States Environmental Protection Agency (USEPA). (1996). Emission factor documentation for AP-42 Section 3.3 - Gasoline and diesel industrial engines, In AP42, 5th Edition, Volume I Chapter 3: Stationary Internal Combustion Sources. Retrieved from http://www.epa.gov/ttn/chief/ap42/ch03/final/c03s03.pdf

Wang, H., Fu, L., Zhou, Y., Du, X., \& Ge, W. (2010). Trends in vehicular emissions in China's mega cities $\begin{array}{lllll}\text { from } 1995 \text { to } 2005 . & \text { Environmental Pollution, } & 158, & 394-400 .\end{array}$ http://dx.doi.org/10.1016/j.envpol.2009.09.002

Wiessner, P. (1974). A functional estimator of population from floor area. American Antiquity, 39, 343-350. http://dx.doi.org/10.2307/279593

World Gazetteer. (2010). Nigeria: largest cities and towns and statistics of their population. Retrieved from $\mathrm{http} / /$ www.world-gazetteer.com/wg.php? $\mathrm{x}=\& \mathrm{men}=$ gcis\&lng=en\&des=wg\&srt=npan\&col=abcdefghinoq\& $\mathrm{msz}=1500$ \&ge $\mathrm{o}=-158$

Zhang, J., \& Marawska, L. (2002). Combustion sources of particles: 2. Emission factors and measurement methods. Chemosphere, 49, 1059-1074. http://dx.doi.org/10.1016/S0045-6535(02)00240-0

Zhang, J., Smith, K. R., Ma, Y., Ye, S., Jiang, F., Qi, W., ... Thorneloc, S. A. (2000). Greenhouse gases and other airborne pollutants from household stoves in China: a database for emission factors. Atmospheric Environment, 34, 4537-4549. http://dx.doi.org/10.1016/S1352-2310(99)00450-1 


\section{Notes}

Note 1. Based on the following conversion factors: $3.78541178 \mathrm{Litres}=138,690 \mathrm{Btu}$; $1 \mathrm{MMBtu}=1,000,000 \mathrm{Btu}$.

Note 2. Bio-fuel refers to firewood and charcoal, which constitute a major source of cooking energy in the Niger Delta (NBS, 2009).

Note 3. According to the Intergovernmental Panel on Climate Change (IPCC), domestic activities, defined by the IPCC Code "1A4", encompass residential, commercial and other sources of emissions. Therefore, the estimates presented in Table 2 contain emissions from sources other than domestic cooking and lighting (Source: Netherlands Environmental Assessment Agency, PBL website http://themasites.pbl.nl/en/themasites/edgar/documentation/definitions/index.html).

Note 4. According to Kvamme (1997), logarithmic relationships between settlement size and population are reliable showing "less skewness and the extremity of outlying data points are reduced".

\section{Appendix}

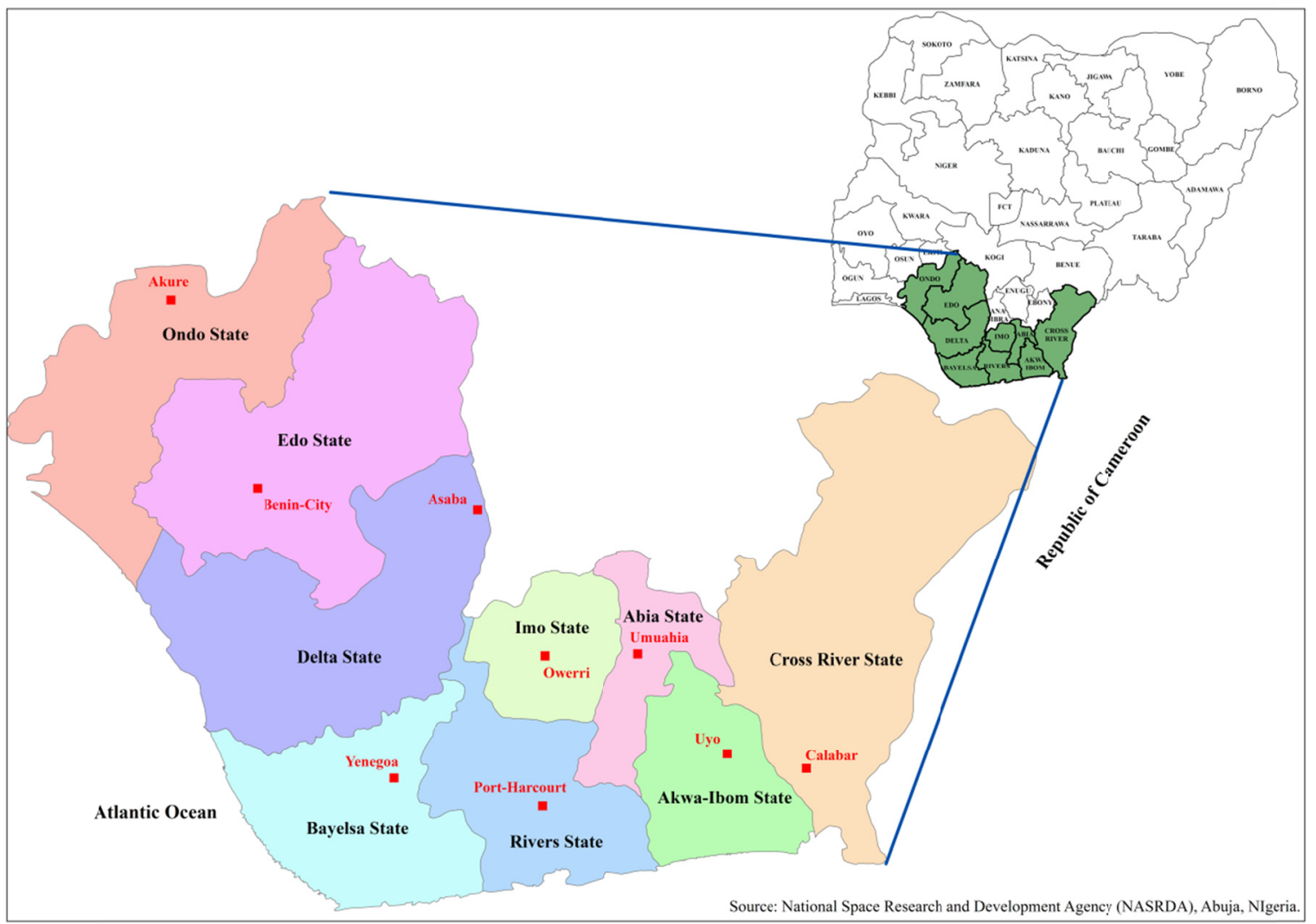

Map of the nine States of the Niger Delta. Inset shows the location of the Niger Delta region within Nigeria. Source of map: NASRDA. 
Emission estimates generated from domestic activities in Nigeria in 2005 based on the percentage contribution from residential sources in the EDGAR database (EC-JRC / PBL, 2010).

\begin{tabular}{cc}
\hline Pollutant / GHG & $\begin{array}{c}\text { 2005 emission estimates from domestic } \\
\left.\text { activities in Nigeria (million } \mathbf{~} \mathbf{~ y r}^{-1}\right)\end{array}$ \\
\hline $\mathrm{CO}$ & 4.04 \\
$\mathrm{NO}_{\mathrm{x}}$ & 0.05 \\
$\mathrm{SO}_{2}$ & 0.03 \\
$\mathrm{VOC}$ & 0.40 \\
$\mathrm{CO}_{2}$ & 95.36 \\
$\mathrm{CH}_{4}$ & 0.25 \\
\hline
\end{tabular}

\section{Copyrights}

Copyright for this article is retained by the author(s), with first publication rights granted to the journal.

This is an open-access article distributed under the terms and conditions of the Creative Commons Attribution license (http://creativecommons.org/licenses/by/3.0/). 